\title{
Laboreal
}

Volume $16 \mathrm{~N}^{\circ} 2$ | 2020

Programa de Pesquisa do Curso da Ação

\section{Análise do Curso de Ação e do Projeto Antropocêntrico: contribuições para a conceção de sistemas automatizados}

Análisis del Curso de Acción y Proyecto Antropocéntrico: contribuciones al diseño de sistemas automatizados

Analyse du cours d'action et du projet anthropocentrique: contributions à la conception de systèmes automatisés

Analysis of the Course of Action and the Anthropocentric Project: contributions to the design of automated systems

Francisco de Paula Antunes Lima, Rodrigo Ribeiro, Marcelle La Guardia e Samira Nagem

\section{OpenEdition}

\section{Journals}

Edição electrónica

URL: http://journals.openedition.org/laboreal/16668

DOI: $10.4000 /$ laboreal. 16668

ISSN: 1646-5237

\section{Editora}

Universidade do Porto

\section{Refêrencia eletrónica}

Francisco de Paula Antunes Lima, Rodrigo Ribeiro, Marcelle La Guardia e Samira Nagem, «Análise do Curso de Ação e do Projeto Antropocêntrico: contribuições para a conceção de sistemas automatizados», Laboreal [Online], Volume 16 №2 | 2020, posto online no dia 01 dezembro 2020, consultado o 19 janeiro 2021. URL: http://journals.openedition.org/laboreal/16668 ; DOI: https:// doi.org/10.4000/laboreal.16668

Este documento foi criado de forma automática no dia 19 janeiro 2021.

Laboreal está licenciado com uma Licença Creative Commons - Atribuição-NãoComercial 4.0 Internacional. 


\section{Análise do Curso de Ação e do Projeto Antropocêntrico: contribuições para a conceção de sistemas automatizados}

Análisis del Curso de Acción y Proyecto Antropocéntrico: contribuciones al diseño de sistemas automatizados

Analyse du cours d'action et du projet anthropocentrique: contributions à la conception de systèmes automatisés

Analysis of the Course of Action and the Anthropocentric Project: contributions to the design of automated systems

Francisco de Paula Antunes Lima, Rodrigo Ribeiro, Marcelle La Guardia e Samira Nagem

\section{NOTA DO EDITOR}

Manuscrito recebido em : 11/03/2020

Aceite após peritagem : 11/09/2020

Agradecemos à CEI, que permitiu a realização e divulgação dos resultados da pesquisa de desenvolvimento tecnológica, realizado pela equipe da Situated Consultoria e Pesquisa.

\section{Introdução}

1 No campo da ergonomia, o Programa de Pesquisa Curso da Ação (PPCA) se destaca em diversos aspectos: (i) globalidade dos polos científicos, metodológicos, filosóficos e tecnológicos considerados no programa de forma orgânica; (ii) formalização de pressupostos ontológicos (sociais e existenciais), epistemológicos, tecnológicos e 
metodológicos (descrição empírica, análise multiníveis), com ênfase na teoria da atividade; (iii) análise da relação entre atividade humana e atividade política; (iv) proposição de integração entre dimensões micro e macrossociais por meio de análises multiníveis, permitindo articular economia e atividade humana e, no plano prático, ampliar a engenharia das situações ao espaço e à organização; e (v) proposição de uma teoria da subjetividade ou filosofia da experiência (um monismo com subjetividade), coerente com a atividade e cognição situadas, sem necessidade de recorrer a um conceito de sujeito, que levaria a uma concepção dual na relação sujeito-objeto.

O PPCA vem sendo formalizado em diversas obras (Theureau, 1992; Pinsky, 1992; Theureau \& Jeffroy, 1994; Theureau, 2004, 2006, 2009, 2015b, 2019), cuja complexidade torna o conjunto e seus aspectos específicos de difícil apreensão pelos pesquisadores que assumem perspectivas próximas, mesmo entre os ergonomistas. Essas dificuldades vão da pesquisa empírica, considerada demasiadamente "pesada", às reflexões teóricas mais avançadas.

3 Este artigo aborda um aspecto específico do Programa de Pesquisa Tecnológico (PPT), um polo no interior do PPCA. A questão trabalhada é a contribuição do PPCA à concepção ergonômica, mostrando sua eficácia em situações complexas, mesmo sem recorrer ao sistema conceitual em seu conjunto e sem desenvolver modelos do curso da ação detalhados. Hoje, no campo mesmo da ergonomia da atividade, observa-se um retrocesso em teorias e metodologias de análise da atividade. Essa afirmação pode parecer paradoxal, mas o movimento de desenvolvimento de quadros teóricos para suportar as intervenções ergonômicas, iniciado nos anos 1980 e no seio do qual a teoria do curso da ação ocupou um lugar central (Wisner, 2004), tomou rumos que deixam a ergonomia sem a necessária base teórica para descrever empiricamente o seu objeto central: a atividade de trabalho. Sem isso, como será discutido, a intervenção ergonômica fica limitada em sua capacidade de orientar os projetos de engenharia para torná-los mais aderentes à atividade de trabalho.

4 Nas outras tendências que se construíam ao longo dos anos 1980, a elaboração de uma teoria da atividade não foi priorizada. $\mathrm{Na}$ formalização mais geral do método, em Compreender o trabalho para transformá-lo, a atividade permanece um lugar localizado entre o trabalho prescrito e o trabalho real, comumente repetida na diferença entre tarefa e atividade, sem que essa "atividade" seja colocada no centro das reflexões teóricas a partir de descrições empíricas pertinentes. Sintomaticamente, a tarefa foi desdobrada em tarefa real e tarefa efetiva, enquanto a atividade permanece um conceito não analisado, assim como a "experiência".

5 Mesmo quando a ergonomia foi apropriada pela ergologia como sua propedêutica, ainda que a atividade de trabalho, e mais tarde a atividade humana, seja colocada como objeto central da reflexão, ela serviu mais para fundar uma filosofia da atividade do que uma praxeologia de base empírica. Isso não desdiz do potencial teórico da ergologia e de sua capacidade para produzir transformações do trabalho, mas sim de sua eficácia limitada para atuar em projetos de engenharia.

6 Atualmente ergonomistas se aproximam da teoria da atividade de Engeström, que pode ter algum interesse no plano da condução da intervenção. Porém, seus modelos analíticos, descritos em termos de sistema de atividades, ainda são demasiadamente estáticos para descrever empiricamente a dinâmica da atividade em todas suas nuanças e complexidades, em especial seus momentos criativos. A noção de "aprendizagem expansiva" (Engeström, 1987) faz parecer que existe uma análise da dinâmica da 
atividade, mas a descrição em nível empírico se resume a constatar estados consecutivos, sem que os processos ativos e cognitivos dinâmicos subjacentes à expansão sejam evidenciados e analisados.

7 Mesmo na clínica da atividade, que se fundamenta em conceitos dinâmicos, até mesmo dando primazia à transformação em relação à compreensão (Clot, 2010), devido ao seu foco privilegiado no "real da atividade", a descrição da atividade real permanece, por definição, limitada, dando-se mais ênfase às controvérsias profissionais e ao complexo jogo de destinação subjetiva das ações a diversos atores, aos quais se atribui os resultados observáveis em termos de desenvolvimento da atividade e do métier (ver, por exemplo, Fernandez, 2004 e Simonet, 2009). Não se trata, aqui, de questionar as opões teóricas da clínica da atividade ou sua capacidade para produzir transformações do trabalho, mas sim a pertinência da precedência da transformação em relação à compreensão quando se trata de intervir em projetos tecnológicos mais amplos, mesmo se o papel central dos instrumentos é reconhecido pelas referências à teoria da atividade instrumental de Vygotski.

Os "espaços de debate do trabalho" (EDT), que hoje tendem a se difundir nas intervenções ergonômicas (Falzon, 2013; Rocha, Mollo, Daniellou, 2015; Rocha, 2015), também fazem economia de análises sistemáticas e aprofundadas da atividade de trabalho, privilegiando dispositivos de intervenção que incluem, de forma direta, metodologias de análise levadas a cabo pelos próprios trabalhadores. Por exemplo, Rocha (2015) anima os EDT com base em evidências registradas em fotos pelos eletricistas o que, evidentemente, restringe as análises ao que pode ser percebido diretamente e fotografado, aproximando a análise ergonômica dos espaços de expressão, como proposto na Análise Coletiva do Trabalho, desenvolvida por Leda Leal Ferreira (2015), realizada sem ter acesso direto às situações de trabalho. Os EDT se aproximam também dos Grupos de Encontro do Trabalho (GET), usados na ergologia como método de expressão da experiência (Trinquet, 2010). No entanto, se a ergologia, cujo ponto forte é ser uma filosofia do trabalho, pode se satisfazer com grupos de expressão, na ergonomia isso é um evidente retrocesso e mesmo um contrassenso quando se considera seu objetivo de transformar o trabalho pelo projeto de novas situações.

9 No conjunto, essas abordagens mais recentes, seja da ergonomia ou das clínicas do trabalho, acabam limitando a contribuição dos analistas do trabalho na solução de problemas mais complexos, que exigem análises que possam apreender a dinâmica da atividade real em situações concretas. Alguns exemplos são problemas que integram vários níveis organizacionais, da atividade individual-coletiva às interfaces organizacionais, ou projetos tecnológicos complexos, como sistemas automatizados e salas de controle (Lima, Duarte, Resende, Garrigou e Carballeda, 2015).

Todas essas abordagens podem contribuir para mudanças e transformações positivas nas condições de trabalho e para desenvolver a própria atividade, mas isso se consegue sem passar por uma formalização rigorosa da atividade real e dos métodos necessários para analisá-la, base para seu posterior desenvolvimento. Sem dúvida, projetos conduzidos segundo a démarche da ergonomia de concepção, seja na condução de projetos (Daniellou, 2007) ou na concepção de artefatos (Folcher e Rabardel, 2007), permite gerar instrumentos mais apropriados aos trabalhadores e usuários ${ }^{[1]}$. No entanto, mesmo nesses casos, aspectos mais complexos e dinâmicos ainda são deixados aos projetistas ou à expressão espontânea dos trabalhadores envolvidos nas equipes de 
projetos colaborativos. Os casos empíricos discutidos neste artigo mostram não apenas a pertinência da teoria do curso da ação no projeto de novas situações de trabalho, mas também que uma praxeologia empírica que descreva a dinâmica da atividade é necessária para tratar de interfaces H-H (formação e organização do trabalho) e H-M (automação) se quisermos dar conta de problemas mais complexos com propriedades dinâmicas no interior de sistemas automatizados (H-H-M).

11 Problemas de projeto de interfaces não são novos. Desde que a automação começou a se difundir nos anos 1950, as tentativas de desenvolvimento de tecnologias antropocentradas se sucederam sem muito sucesso. As análises propostas neste artigo permitem formular a hipótese de que uma das principais razões para esse fracasso histórico foi a falta de uma teoria da atividade, com recursos conceituais e metodológicos que possibilitassem, de fato, projetar as interfaces entre homens e máquinas, ou seja, integrar os aspectos social e técnico em projetos sociotécnicos. Essa história recente demonstra que princípios gerais das abordagens antropocêntricas são importantes para abrir espaços para projetos sociotécnicos, mas ainda pouco operacionais para integrar o social, o subjetivo e o técnico.

Os casos empíricos analisados neste artigo resultam de uma intervenção em uma empresa de geração de eletricidade, que opera Pequenas Centrais Hidrelétricas (PCHs). No momento da intervenção, a empresa passava por uma reorganização importante, com a automação das PCHs e operação em sala de controle remota (a $100 \mathrm{Km}$ de distância), implicando redução do pessoal operacional e organização do trabalho em rodízio, o que exigia polivalência dos trabalhadores, antes lotados em PCHs específicas. Por isso, existia também uma demanda para formalizar os saberes tácitos dos operadores de campo que iriam se aposentar, sair da empresa ou supervisionar mais de uma PCH.

Dessa intervenção serão discutidos os produtos que foram desenvolvidos, passíveis de uso em outras situações de trabalho e/ou projeto: (1) "árvores de julgamento" e "árvores sequenciais" baseadas no curso da ação de operadores, operacionalizando o conceito de "objetos intermediários da formação" (análogos aos "objetos intermediários de concepção", propostos por Vinck, 2013); (2) um "modelo analítico para automação antropocêntrica e apropriável", com base em representamens característicos das atividades críticas analisadas; e (3) um "modelo analítico de cooperação: operação local versus operação remota", que atua como um "objeto intermediário de co-operação", entre operadores de campo e da sala de controle remota.

Além da contribuição tecnológica para o PPT, os produtos resultantes desta intervenção buscam também resolver uma questão até então não tratada dentro PPCA: como agir sobre o que não é explicitável da atividade, ou seja, sobre a parte tácita da experiência que não pode ser narrada, mostrada ou comentado? É sabido que as descrições do curso da ação servem para projetar situações de trabalho diversas. Porém, além desse uso direto, as árvores de "julgamento" e "sequenciais" permitem que julgamentos tácitos realizados por operadores experientes sejam parcialmente explicitados e discutidos entre os próprios experts (levando ao compartilhamento e à discussão de diferentes "estilos") e quando da interação desses com os novatos (educando a atenção dos últimos) ${ }^{2}$. A organização dos julgamentos tácitos explicitados nas árvores, do simples ao complexo ou dentro da sequência de ações no interior de uma atividade, funciona como um instrumento para que o novato possa desenvolver sua expertise 
progressivamente, ampliando em bases seguras seus espaços de autonomia e a sua polivalência.

Além desta introdução, o artigo está estruturado em mais 5 seções. Em um breve percurso histórico, retomamos as primeiras tentativas do projeto ESPRIT da Comunidade Europeia, no âmbito do qual se procurou desenvolver tecnologias antropocêntricas, associando engenheiros e cientistas sociais, propondo uma explicação dos insucessos pela falta de uma teoria da atividade empiricamente fundada (seção 2). Isso nos leva diretamente ao interesse da teoria do curso da ação para o desenvolvimento de artefatos tecnológicos que sejam apropriados e apropriáveis pelos operadores, sustentando "o caráter antropologicamente constitutivo da técnica" (Stiegler, 2018). Na questão da técnica no âmbito do PPCA, o artigo se debruça mais especificamente sobre o programa tecnológico, que hoje se apresenta na forma de uma "engenharia de situações de trabalho", procurando articular artefatos materiais, organização do trabalho e formação (seção 3). A efetividade e fertilidade desse programa é atestada pelos produtos de formação, automação e operação coletiva H-H$\mathrm{M}$, oriundos da intervenção nas PCHs (seção 4). Em conclusão, acentuamos nossa contribuição ao polo tecnologia do PPCA e a extrapolamos para o debate atual em torno da indústria 4.0, que revela a fala de memória histórica da engenharia, teimando em repetir o mito da fábrica sem homens, já presente nos debates do projeto antropocentrado desde os anos 1970.

\section{Impasses dos projetos sociotécnicos e antropocêntricos}

16 Na esteira dos movimentos sociais e trabalhistas dos anos 1960, surgiram várias abordagens alternativas à concepção tecnocêntrica da engenharia. Nesse movimento podemos relembrar o sociotechnical systems design (STSD) (Eijnatten, 1993), cujas raízes remontam ao trabalhos de Emery e Trist do Tavistock Institut, no final dos anos 1940; o work-oriented design (Ehn, 1988); o projeto antropocêntrico (Corbett, Rasmussen, \& Rauner, 1991; Brödner, 1990; Brödner, 1992); a social shaping of technology (Corbett, Rasmussen, \& Rauner, 1991); activity-oriented design (Engeström, 1987; Bödker, 1997; Nardi, 1997), sem mencionar abordagens críticas como a construção social da tecnologia (Bijker, Hugues, \& Pinch, 1989). Essas abordagens compartilham um interesse comum de integrar homens e artefatos técnicos atuando no projeto, que abarca pelo menos três elementos ou aspectos dos sistemas H-M: 1) os artefatos propriamente ditos; 2) o trabalho, seja a formação dos trabalhadores ou a organização do trabalho; e 3) as interfaces entre homens e máquinas. Metodologicamente, também se assemelham por adotarem métodos participativos, mais ou menos aprofundados.

17 Ainda é motivo de debate porque essas abordagens encontraram dificuldades para se difundirem, mesmo quando produziram resultados superiores aos projetos convencionais tecnocentrados. Antagonismos políticos e estratégias empresariais são apontados $^{[3}$, mas, sem desconsiderar essas determinações político-sociais mais amplas, há problemas não resolvidos no nível do próprio projeto dos sistemas H-M. As experiências de cooperação entre as ciências sociais e as engenharias não se consolidaram o suficiente para constituir, de fato, um "paradigm that changed the workplace", para retomar o título otimista do livro de Frans Eijnatten (1993) sobre o STSD. Nossa hipótese é que essas experiências careciam de uma teoria consistente sobre 
a atividade humana que possibilitasse orientar o projeto de engenharia, conceber as interfaces e projetar a organização do trabalho de forma integrada. Essa hipótese pode ser verificada retomando algumas experiências emblemáticas dos anos 1970 e 1980.

Corbett, Rasmussen e Rauner (1991) coordenaram, no âmbito do programa ESPRIT, equipes multidisciplinares em três países europeus (Inglaterra, Dinamarca e Alemanha), para desenvolver uma planta CIM (Computer Integrated Manufacturing) antropocentrada. Nesse processo cunharam o termo de "social shaping of technology" na intenção de promover o diálogo entre engenheiros e cientistas sociais que participavam do projeto. Com equipes trabalhando em três países, cada um com um subprojeto, pôdese experimentar arranjos sociais diferentes e relacioná-los a resultados diferentes, mais ou menos próximos aos princípios do design antropocêntrico. No desenvolvimento, os projetos abordaram, com maior ou menor ênfase numa ou noutra equipe, três aspectos: projeto do artefato técnico, design de interfaces e projeto organizacional (organização do trabalho e formação). No balanço final das experiências, os autores formalizam o conceito de "crossing the border", pelo qual tentam generalizar os resultados em termos de processo social de concepção, mais como proposição metodológica do que como resultado efetivo das experiências, que ficaram aquém do objetivo proposto.

$\mathrm{Na}$ vertente germânica, Böhle e Milkau (1988) mostram o quanto se conseguiu aproximar atividade humana e projeto técnico, propondo o conceito de atividade subjetivante ${ }^{[4]}$. Embora seja um estudo de sociologia do trabalho conduzido de forma essencialmente analítica, os autores tiram consequências para o projeto de sistemas automatizados que permitam o desenvolvimento da atividade subjetivante em novas configurações e distribuições de funções entre homens e máquinas. As propostas abrangem também a formação e a organização do trabalho, inclusive a cooperação entre operadores de produção e projetistas. A situação analisada foi a introdução de máquinas de usinagem CNC (comando numérico computadorizado), substituindo as máquinas manuais, nas quais havia um contato direto dos operadores com o equipamento e com o material usinado. Todo o corpo do trabalhador estava engajado na realização do trabalho, que envolvia os sentidos do tato, audição, odor, visão e propriocepção. Com a introdução do $\mathrm{CNC}$, cria-se um distanciamento que impede o contato direto com a máquina, dificultando mesmo a visão. Porém, os autores mostram como os operadores de sistemas automatizados conseguem reconstituir a atividade subjetivante com a percepção de ruídos significativos. Sem isso eles não conseguiriam antecipar a quebra de uma ferramenta ou seu desgaste. A conclusão geral é que o engajamento do corpo não acontece apenas na operação de máquinas manuais, o que é de se esperar, mas também em sistemas automatizados. Isso torna necessário refletir sobre as condições de desenvolvimento da atividade subjetivante na operação de máquinas $\mathrm{CNC}$, sobretudo quando a experiência com máquinas manuais tende a se tornar mais rara para as novas gerações de operadores que não viveram a transição. Interessante, para nossa discussão, são as recomendações práticas para resolver os problemas evidenciados por meio do projeto do trabalho, envolvendo formação, organização do trabalho e equipamentos.

o reconhecimento da atividade subjetivante desaconselha a prática de alocar várias máquinas a um mesmo operador, pois mesmo máquinas automáticas continuam sendo únicas e exigem um saber íntimo do operador para dominar a "sua" máquina. Preencher supostos "tempos mortos" com outras tarefas impede que o operador acompanhe sua máquina e perceba as variações de ruído que indicam desgaste da 
ferramenta ou outra variação do processo (aço, fluído refrigerante etc.). A prática de job rotation é também desaconselhada, pois dificulta o desenvolvimento dessa percepção refinada da máquina. Com as proteções, o ponto de usinagem fica quase inacessível ao operador, que conta apenas com o sentido da audição para acompanhar o processo. Permitir o acesso ou visualização direta, sobretudo no início de um novo lote, ajudaria a estabilizar o processo nesse momento crítico.

Em termos de lógica de programação, também aqui os operadores necessitam fazer intervenções que normalmente são proibidas quando se adota a programação centralizada:

No tocante à organização do trabalho, as margens de experimentação sobre as máquinas devem ser integradas como componentes do comportamento de trabalho. Como mostramos, isso é uma condição importante para um comércio seguro e otimizado com as máquinas. O princípio seguinte deve ser observado, inclusive nas máquinas $\mathrm{CNC}$ : "aquele que não experimenta nada e que não ousa nada, não utilizará jamais a máquina de forma otimizada, ele não terá nenhuma segurança no seu domínio" (Böhle \& Milkau, 1998, p. 143, tradução livre).

Se nas máquinas manuais, a autonomia e o conhecimento tácito dos operadores, verdadeiros artesãos da usinagem, eram reconhecidos e valorizados, nos sistemas automatizados ainda se acredita que os operadores são meros "apertadores de botões" e não teriam muito a dizer aos programadores. No entanto, também aqui a regra deveria ser a cooperação entre serviço de programação e a produção estabelecendo um diálogo no pleno sentido do termo:

Mas é preciso também que sejam criadas as condições que permitirão aos operadores, em função de seu saber particular e de sua experiência prática com as máquinas, de fazer valer certas proposições e críticas em relação à programação e à gestão da produção. Isso é bem pouco levado em conta atualmente. Até agora, a cooperação é possível somente quando a iniciativa parte dos serviços de programação ou de gestão da produção. (Böhle \& Milkau, 1998, p. 144, tradução livre)

Para suprir a carência de sentidos necessários para reconstruir a atividade subjetivante, os operadores de $\mathrm{CNC}$, para acompanhar o processo de usinagem e conseguir antecipar problemas e otimizar o funcionamento da máquina, desenvolvem o que os autores denominam de "sensibilidade abstrata". Na impossibilidade de se ter um feedback imediato da usinagem pelos sentidos e pelo corpo, os operadores devem representar o funcionamento da máquina:

Essas representações não são apenas o fruto da imaginação. Elas repousam sobre experiências reais transpostas e aplicadas a situações nas quais elas não são possíveis da mesma maneira. Elas apresentam características de uma "sensibilidade abstrata". Elas são "sensíveis porque, como no caso de experiências e de percepções sensoriais reais, elas foram desenvolvidas por meio de e com base nos diferentes sentidos. Isso é caracterizado pelo fato de que a representação das operações é "percebida em imagens" ${ }^{5 "}$ e que os trabalhadores "veem" os sequenciamentos representados; de modo análogo, se estabelecem igualmente 
associações pelo comércio táctil com o objeto: a gente acredita ter o material na mão, senti-lo, se bem que a gente não o toque realmente. Essa percepção sensível é “abstrata" porque ela é separada, "abstraída" do sequenciamento e dos objetos concretos, assim como no pensamento conceitual, se abstrai das realidades concretas. (Böhle \& Milkau, 1998, p. 114, tradução livre)

Pode-se estranhar a expressão de "sensibilidade abstrata", que conjuga representações abstratas, imagens, com percepções sensíveis, mas importa reconhecer os fenômenos a que remete. Veremos, nos casos empíricos apresentados abaixo, que essas impressões subjetivas aparecem na forma de abstrações como "sentir o canal", pelas quais o operador de uma PCH ajusta o fluxo de água de modo a otimizar a geração de energia. Da mesma forma, com a ajuda dos objetos intermediários desenvolvidos para orientar a formação dos operadores das salas de controle remotas, pode-se verificar a emergência de representações ou imagens que até então eles não dispunham. Mas essas representações, embora reconhecidas nas abordagens antropocêntricas, ainda não são produzidas de forma organizada ou com meios sistematizados, limitações que a abordagem do curso da ação consegue superar graças à sua compreensão, desde cedo, da ergonomia como uma tecnologia.

\section{Teoria do curso da ação e o programa tecnológico}

A "teoria do curso da ação" (TCA) desenvolve-se em torno de um programa de pesquisa empírica em antropologia cognitiva e de um programa de pesquisa tecnológica. Em termos práticos, seu objetivo central é oferecer descrições suficientemente detalhadas da atividade (nesse sentido se define como uma praxeologia empírica), que possam gerar modelos de concepção pertinentes para os projetistas. Na introdução de Méthode Réfléchie, Theureau (2009), ao apresentar o programa de pesquisa filosófica que se articula aos dois precedentes, anuncia a futura publicação de obras mais específicas, dentre as quais trabalhos que especificam o programa de pesquisa tecnológica. Neste artigo, nos apoiamos, sobretudo, na obra coletiva (Theureau \& Jeffroy, 1994), onde as contribuições do curso da ação ao projeto de situações de trabalho informatizadas estão mais desenvolvidas, sendo possível situar a questão da passagem da descrição da atividade às recomendações de projeto. Embora não tenha sido apropriada entre os ergonomistas, como acontece em outras áreas como projeto de sistemas informatizados e educação, notadamente em STAPS (Sciences et Techniques des Activités Physiques et Sportives), a teoria do curso da ação é, no nosso entender, o projeto mais avançado e ambicioso de teorização e formalização de uma praxeologia empírica no campo da ergonomia, o que não implica dizer que todos os problemas foram resolvidos, como sugere sua caracterização como uma teoria "barroca" (Theureau, 1992). Neste artigo, discutimos especificamente como fazer avançar o programa tecnológico, descrevendo um caso (seção 5), que resultou em intervenções integradas em três campos: formação, especificações de automação e organização do trabalho (operação conjunta sala de controle-campo).

o pressuposto geral, compartilhado com outras abordagens que se inspiram na teoria da atividade instrumental de Vygotski, é que o desenvolvimento humano passa necessariamente pelo projeto apropriado de situações de trabalho, ou sejam implica reconhecer o "caráter antropologicamente constitutivo da técnica", como proposto por 
Stiegler (2018), que distingue três tipos de gêneses de um indivíduo humano em um dado momento:

- “a gênese, tendo por produto a memória genética: a transmissão genética;

- a epigênese, que tem por produto a memória nervosa: o que vem da aprendizagem e da formação no curso de uma vida;

- a epi-filogênese, que tem por produto a memória tecnológica (que associa técnica e linguagem e, mais geralmente, tudo o que faz signo): o que cada geração encontra como já dado, construído pela técnica." (Theureau, 2015a, p. 308)

Essa imbricação entre desenvolvimento humano e desenvolvimento da técnica tem, segundo Theureau, consequências importantes para a concepção ergonômica que, inicialmente pensada em termos de "ajuda", deve ser repensada em termos de "apropriabilidade da técnica". Ou seja, "pensar a concepção do conjunto de uma maneira que ajude efetivamente o homem em situação, mas também, e sobretudo, participar de uma produção, se não de uma humanidade desejável, pelo menos de um aspecto inerente a uma tal humanidade desejável (Theureau, 2015a).

Mas como traduzir as descrições da atividade situada, sempre contextualizada, dinâmica e contingente, em recomendações de projeto que, no fim das contas, opera um "congelamento" ou reificação do trabalho? As noções do curso da ação são dinâmicas e dizem respeito a realidades transitórias "no sentido em que elas se referem a recortes com uma espessura temporal mais ou menos grande em um fluxo" (Theureau \& Jeffroy, 1994, p. 245. Tradução livre). No entanto, pelo menos no que concerne aos interpretantes adquiridos, pode-se constatar uma certa estabilidade dos tipos:

“A hipótese da composição dos interpretantes adquiridos pelos tipos e relações entre tipos implica certa estabilidade temporal e situacional entre as diferentes sortes de tipos e relações entre tipos" (Theureau \& Jeffroy, 1994, p. 222, tradução livre).

"Aliás, é notável que vários estudos de ergonomia e psicologia do trabalho empregam o termo "esquema" a respeito de "regras" mais ou menos locais, recortadas, mutáveis, observadas na análise de dados da atividade, sem definir alguma arquitetura de esquemas encastrados, isto é, sem empregar a "teoria dos esquemas"” (Theureau \& Jeffroy, 1994, p. 227, tradução livre).

Em relação ao processo de projeto, interessa-nos sobretudo os modelos de transformação produzidos a partir das descrições e análises do curso da ação. Nesse sentido, a diferença entre "cursos da ação tipos" e os "esquemas" ressalta as vantagens do primeiro quanto às relações que podem ser estabelecidas entre os modelos e as situações projetadas, a saber:

"Os tipos de relações entre tipos evidenciados nos estudos empíricos do curso da ação são mais locais, recortados e mutáveis.

Igualmente, as relações entre tipos aparecem bem mais variadas que as relações de encastramento. De um lado, um tipo ou uma relação entre tipos pode entrar em uma relação de analogia com outros por um jogo de semelhanças e diferenças bastante variadas. (...) Por outro lado, um tipo ou uma relação entre tipos podem ser conectados com outros por cada um ou parte dos eventos, ações e comunicações tipos que os compõem". (Theureau \& Jeffroy, 1994, p. 227, tradução livre).

30 Essas características dinâmicas dos tipos, reconhecidas, aqui, no momento de descrever a atividade, terão a fortiori maiores consequências quando se trata de fornecer modelos da atividade aos projetistas. $\mathrm{O}$ curso da ação é objeto de descrições detalhadas, que 
permitem formalizar modelos de análise em níveis diferenciados, globais ou locais, de organização da atividade ${ }^{[6]}$.

"O modelo de construção global é um conjunto coerente de estruturas significativas que revelam regularidades subjacentes ao desenvolvimento dos cursos da ação como um todo. (Theureau \& Jeffroy, 1994, p. 98, tradução livre).

O modelo de construção local é um modelo de análise do surgimento a cada instante de uma ou outra das unidades significativas elementares do curso da ação, isto é, de uma ação, comunicação, interpretação ou focalização. (Theureau \& Jeffroy, 1994, p. 99, tradução livre).

Os modelos de transformação (sincrônicos e diacrônicos) do curso da ação ligam as características da organização intrínseca do curso da ação (engendramento, composição) com as condições externas (do estado dos atores, de sua situação e de seu referencial). Nós os denominamos assim porque eles permitem passar do curso da ação (de um ator dado, em uma dada situação, a um momento dado) a um outro. Esses modelos de transformação do curso da ação podem ser desenvolvidos em modelos do curso da ação e de seus efeitos (concernentes ao estado dos atores, suas situações e seu referencial)". (Theureau \& Jeffroy, 1994, p. 99, ênfases no original, tradução livre). Esses princípios de tradução das análises dinâmicas do curso da ação, em termos de recomendações de projeto, foram anunciados desde as primeiras formalizações da TCA:

"As noções teóricas que apresentamos permitem construir modelos dos cursos da ação estudados. (...) São os modelos do curso da ação e não modelos do usuário (seja um mecanismo que descreve seu funcionamento, seja uma representação do funcionamento do sistema). Esses modelos são de diferentes tipos segundo a natureza dos cursos da ação estudados. Por exemplo, para um trabalho de digitação, eles colocam em evidência os COA-TYPES organizando a digitação (Pinsky \& Theureau, 1987); para as atividades de resolução de problemas de utilização de microcomputadores, eles descrevem os raciocínios desenvolvidos pelos operadores (Jeffroy, 1987)". (Pinsky, 1992, p. 117-8, tradução livre).

No entanto, outras dificuldades metodológicas ainda devem ser superadas, na construção dessa teoria "barroca" da atividade de trabalho, para passar da descrição, global ou local, aos modelos operacionais da perspectiva dos projetistas. No quadro teórico do curso da ação, esta função é desempenhada pelas hipóteses concernentes à transformação do curso da ação.

"Essas hipóteses relacionam características da organização intrínseca (ou construção) dos cursos da ação aos constrangimentos e efeitos extrínsecos (concernentes ao estado dos atores, sua situação e sua cultura)." (Theureau \& Jeffroy, 1994, p. 106, tradução livre).

"Essas hipóteses de transformação do curso da ação podem ser sistematizadas graças à elaboração do que denominamos de modelos de transformação. (...) Tais modelos de transformação têm o interesse de desembocarem diretamente sobre cenários e modelos de concepção". (Theureau \& Jeffroy, 1994, p. 107, tradução livre).

Chegamos, aqui, ao problema da passagem entre a análise da atividade e a formalização de recomendações, que identificamos como questão central em todas as abordagens da ergonomia de concepçãa ${ }^{[7]}$. No entanto, como reconhecem os autores, se as hipóteses de transformação estão presentes em todos os estudos de concepção centrados sobre o 
curso da ação, "raramente foram produzidos esses modelos de transformação" (Theureau \& Jeffroy, 1994, p.107). O caso apresentado a seguir explicita, sobretudo, os representamens que fazem parte dos julgamentos tácitos no interior dos processos decisórios e de resolução de problemas pelos operadores de campo de PCHs. Esses são organizados em modelos relativamente simples da atividade, como árvores de julgamento, os quais, não obstante, são instrumentos eficazes para organizar a formação, a organização do trabalho coletivo de co-operação sala de controle-campo e orientar o projeto dos sistemas automatizados. Os representamens são um dos componentes do signo tetrádico (Figura 1), conceito elementar da TCA desenvolvido a partir do signo triádico de Peirce. A atividade é descrita como um encadeamento de signos tetrádicos, compostos, além dos representamens pela Instância de Referencial e pelo Aberto (anteriormente denominado de objeto). A ação do ator em situação emerge em consequência das inter-relações entre a experiência acumulada do ator e o que lhe vem à cabeça (Instância de Referencial), o que (no mundo) lhe solicita no momento (representamen) e as opções que se descortinam para ele (Aberto) a partir dessa combinação dos componentes do signo. Ao agir, uma nova situação (com um novo representamen, uma instância de referencial modificada e novos possíveis) se configura para o ator e a dinâmica da atividade se revela, então, como um encadeamento de signos e os processos de transformação de seus elementos constituintes.

Figura 1 : Signo tetrádico. Fonte : Theureau (2014)

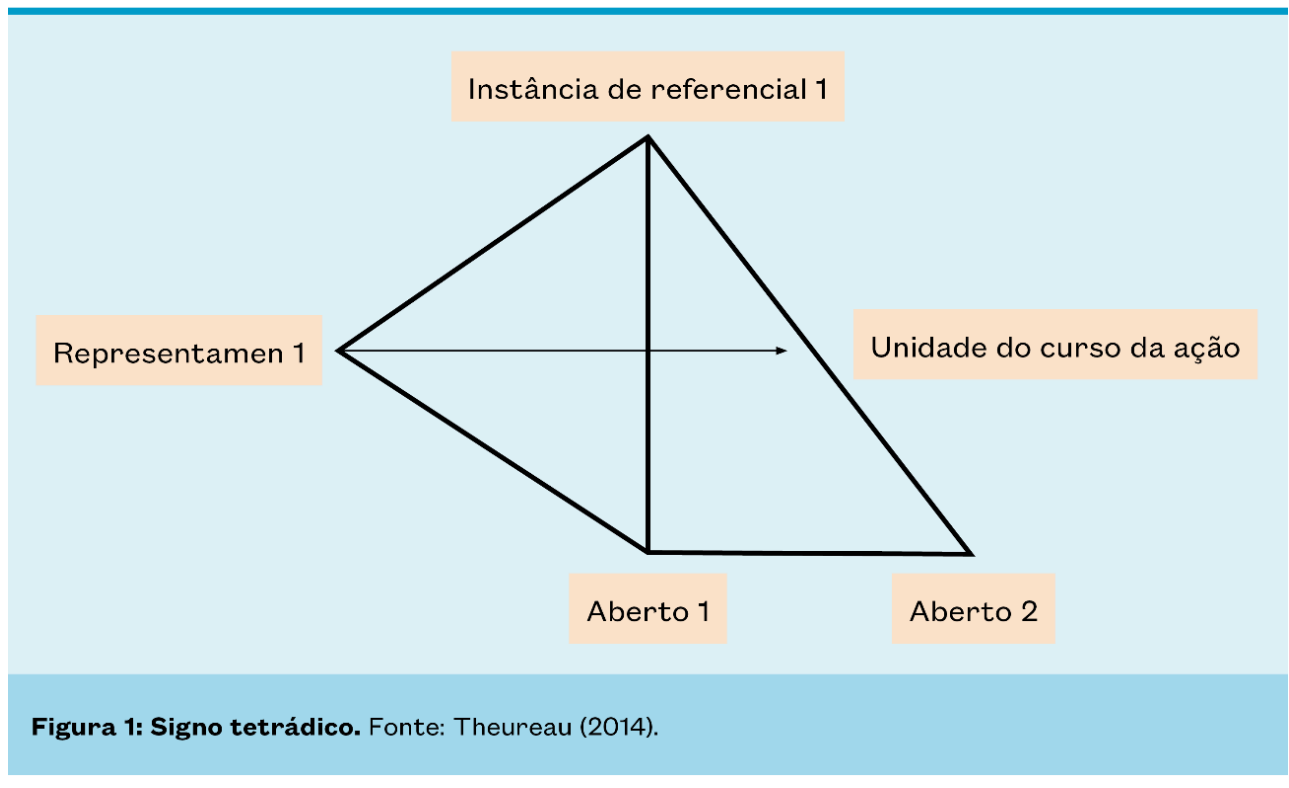

Figura 1 : Signo tetrádico. Fonte : Theureau (2014)

\section{Modelos de transformação em automação de PCHs}

A atividade analisada é a operação local de três PCHs "em cascata", abastecidas por uma barragem de acumulação. A água da barragem é controlada por uma válvula e chega até às usinas pelo rio principal; em cada usina há uma pequena barragem de contenção $\mathrm{e}$ comportas para direcionamento da água do rio para um canal de adução. Tanto o rio principal quanto os canais recebem, ao longo de sua extensão, água de córregos contribuintes. Nos casos dos contribuintes do canal, a mesma estrutura barragem- 
comporta é usada. O complexo energético poderá ser melhor compreendido no esquema da Figura 2.

Figura 2 : Complexo energético das PCHs. Fonte : Situated Consultoria e Pesquisa



Figura 2 : Complexo energético das PCHs. Fonte : Situated Consultoria e Pesquisa

As descrições da atividade em termos de curso da ação foram feitas a partir de registros em vídeos e fotos para apoiar as entrevistas em autoconfrontação. Na construção das árvores de julgamento são utilizados vários símbolos, que chamam a atenção para os principais pontos levantados nas análises de cada uma das atividades e sintetiza os pontos de atenção que são tácitos aos operadores experientes. Apresentamos no Quadro 1 uma breve descrição de cada um desses símbolos e a que se refere dentro da TCA. 
Quadro 1 : Descrição dos principais símbolos usados nas árvores de julgamento

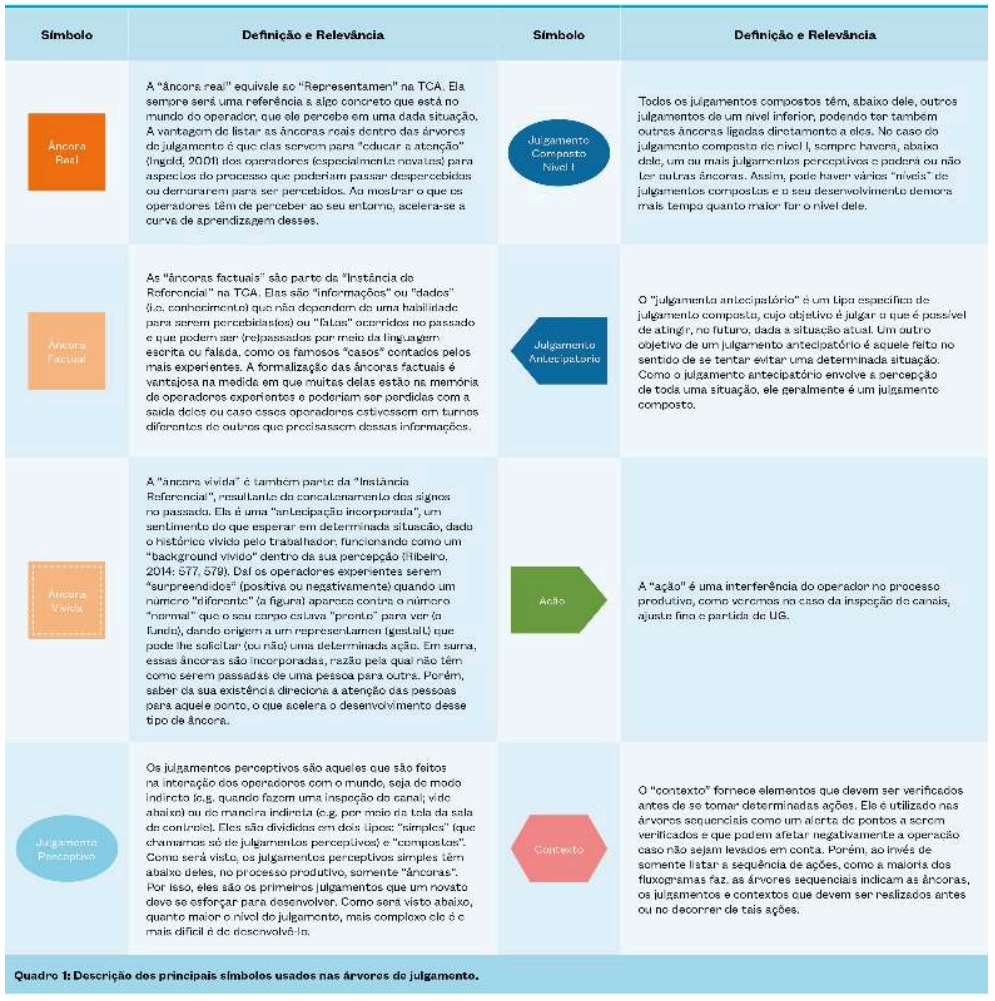

Quadro 1 : Descrição dos principais símbolos usados nas árvores de julgamento

O uso do termo "âncoras" em relação aos termos utilizados na TCA foi adotada por três razões. A primeira foi para facilitar a compreensão e o uso das árvores de julgamento pelos usuários: operadores e engenheiros da empresa. Com essa terminologia, era fácil explicar para todos que as âncoras eram aquelas que serviam para realizar ou "ancorar" os julgamentos realizados pelos experientes. Além disso, a separação em três tipos de âncoras, mostravam aspectos que podiam, respectivamente, serem apontados (âncoras reais), formalizados (âncoras factuais) ou desenvolvidos (âncoras vividas). A segunda razão é que as âncoras factuais e vividas distinguem dois aspectos de natureza diferente no interior da instância de referencial. Por fim, por mais que as âncoras reais tenham nascido a partir de representamens verificados nos cursos de ação analisados, quando todas elas são colocadas em uma árvore de julgamentos (vide Figura 4), elas já não são propriamente "representamens", pois estão "fora" da ação.

Como antecipado, foram criados três produtos durante a intervenção, os quais trazem três tipos de contribuições para o projeto de sistemas H-H-M mais antropocêntricos:

1. Criação de "objetos intermediários da formação", por meio da sistematização do saber tácito dos operadores experientes e sua formalização em "árvores de julgamentos" associadas a atividades específicas e "árvores sequenciais", que apresentam julgamentos tácitos que antecedem sequências de ação. Tais dispositivos facilitam tanto a troca de experiências entre os experts como a aprendizagem dos novatos, compreendendo por "novato" tanto os trabalhadores sem experiência como os trabalhadores com experiência apenas em uma das PCHs, mas que trabalhará em outra;

2. Desenvolvimento de um "modelo analítico para automação antropocêntrica e apropriável", baseado em representamens característicos das atividades críticas analisadas e que, por sua 
vez, operacionaliza princípios de co-operação e apropriabilidade das tecnologias automáticas;

1. Desenvolvimento de um "modelo analítico de co-operação: operação local versus operação remota" que atua como um "objeto intermediário de co-operação" entre operadores de campo e remotos, superando a divisão de funções pensada inicialmente, na qual os operadores da sala de controle tomariam as decisões e os operadores apenas as executariam, contribuindo para transformar um "coletivo de trabalho" em um "trabalho coletivo" (Assunção, 1998; Caroly, 2012).

\subsection{Objetos Intermediários da Formação: Árvores de Julgamento e Sequenciais}

O primeiro produto respondia à demanda inicial de formalizar (tanto quanto possível) os saberes tácitos dos operadores experientes para preservar os saberes específicos de cada usina e facilitar a polivalência, apoiar a formação de novatos e permitir o treinamento rápido de operadores remotos (por meio de visitas guiadas). Isso foi realizado de duas maneiras, por meio de árvores de julgamento e árvores sequenciais. Para exemplificar o primeiro caso, a atividade que discutiremos, pela sua criticidade, é a inspeção de canais de adução. No segundo, apresentamos a árvore sequencial da atividade de partida de Unidade Geradora (UG).

\subsection{1. Árvores de Julgamento}

Os canais de adução do Complexo Energético analisado conduzem a água do leito normal do rio até os condutos forçados das usinas, percorrendo um total de mais de $11 \mathrm{~km}$. As condições estruturais desses ativos são inspecionadas a cada dois ou três dias pelos operadores locais - mesmo em partes de difícil acesso -, para verificar se há vazamentos ou outros indícios que podem levar a rupturas da estrutura, com canais com mais de 60 anos (Figura 3). 
Figura 3 : 0 caminho desde a barragem jogando água no rio pela válvula, a passagem pelo canal de adução e o condito forçado até chegar na PCH. Fonte : Situated Consultoria e Pesquisa

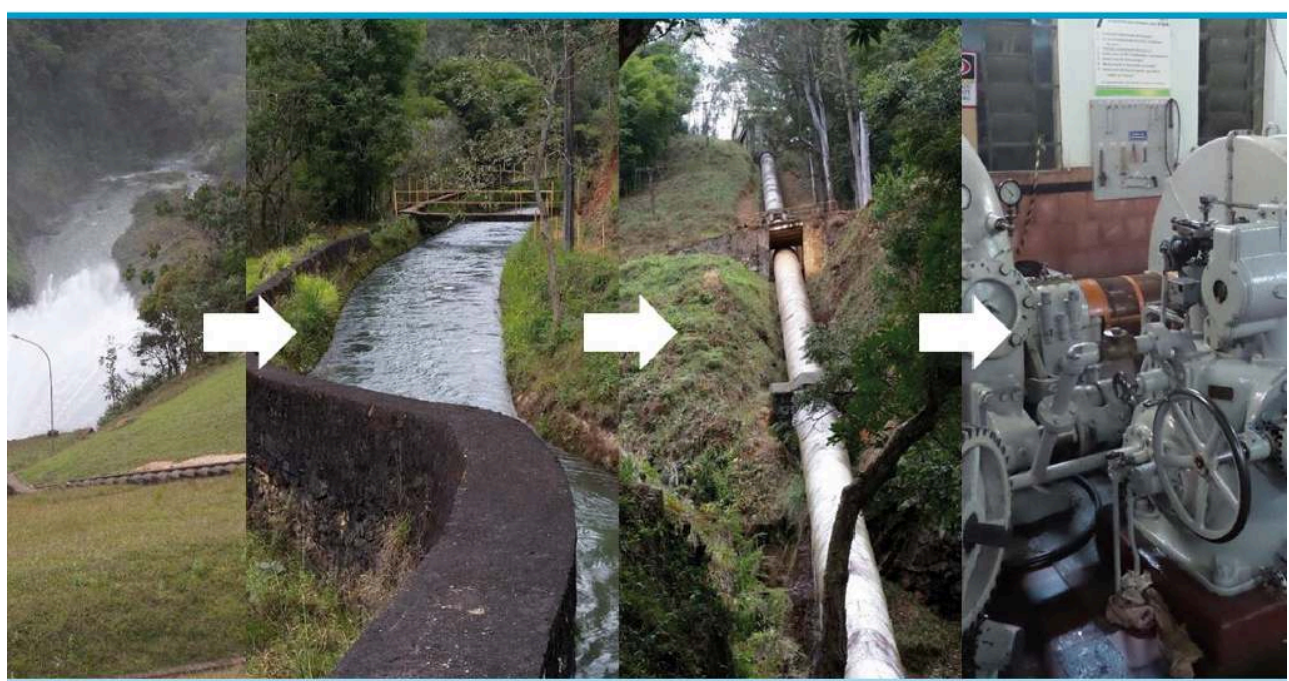

Figura 3: O caminho desde a barragem jogando água no rio pela sua válvula, a passagem pelo canal de adução e o conduto forçado até chegar na PCH. Fonte: Situated Consultoria e Pesquisa.

Figura 3 : O caminho desde a barragem jogando água no rio pela válvula, a passagem pelo canal de adução e o condito forçado até chegar na PCH. Fonte : Situated Consultoria e Pesquisa

40 A inspeção aumenta a segurança das estradas, da comunidade e do meio ambiente e previne acidentes e paradas por ocorrência de rupturas, que impactam tanto a produtividade da usina quanto a "licença social" da empresa, concedida informalmente pela comunidade. Por sua importância, essa atividade foi escolhida para acelerar a aprendizagem dos novatos na identificação de problemas, bem como no desenvolvimento do julgamento de sua criticidade (alta, média ou baixa criticidade). Quando os operadores em campo verificam indícios de vazamento ou quebra, a inspeção é feita imediatamente. $O$ mesmo acontece quando encontram um vazamento ou trinca de baixa criticidade: eles aumentam a frequência da inspeção ao longo da semana, de modo a verificar a evolução da trinca. O julgamento de "criticidade do vazamento ou quebra" é, então, um dos principais julgamentos a serem desenvolvidos para garantir a proteção dos canais, pois, a depender da sua criticidade, o operador age de formas distintas e com um "senso de urgência" apropriado para resolver ou minimizar os possíveis impactos em cada caso.

41 A Figura 4 mostra a árvore de julgamentos para inspeção de canais, com os julgamentos (elipses azuis) e ações (setas verdes). Importa mais para efeitos da discussão, a estrutura e conteúdo geral das árvores do que os detalhes de cada ação ou julgamento, pouco legíveis nas figuras. Tomando como exemplo o julgamento de "criticidade do vazamento ou quebra", pode-se verificar que existem quatro conjuntos de informações e julgamentos (representados pelas setas numeradas que chegam nesse julgamento) para que eles possam ser feitos: (1) o julgamento da natureza do problema; (2) o local do vazamento ou quebra; (3) as âncoras factuais; e (4) o contexto do vazamento ou quebra. 
Figura 4 : Árvore de julgamentos de «Criticidade do Vazamento ou Quebra ». Fonte : Situated Consultoria e Pesquisa

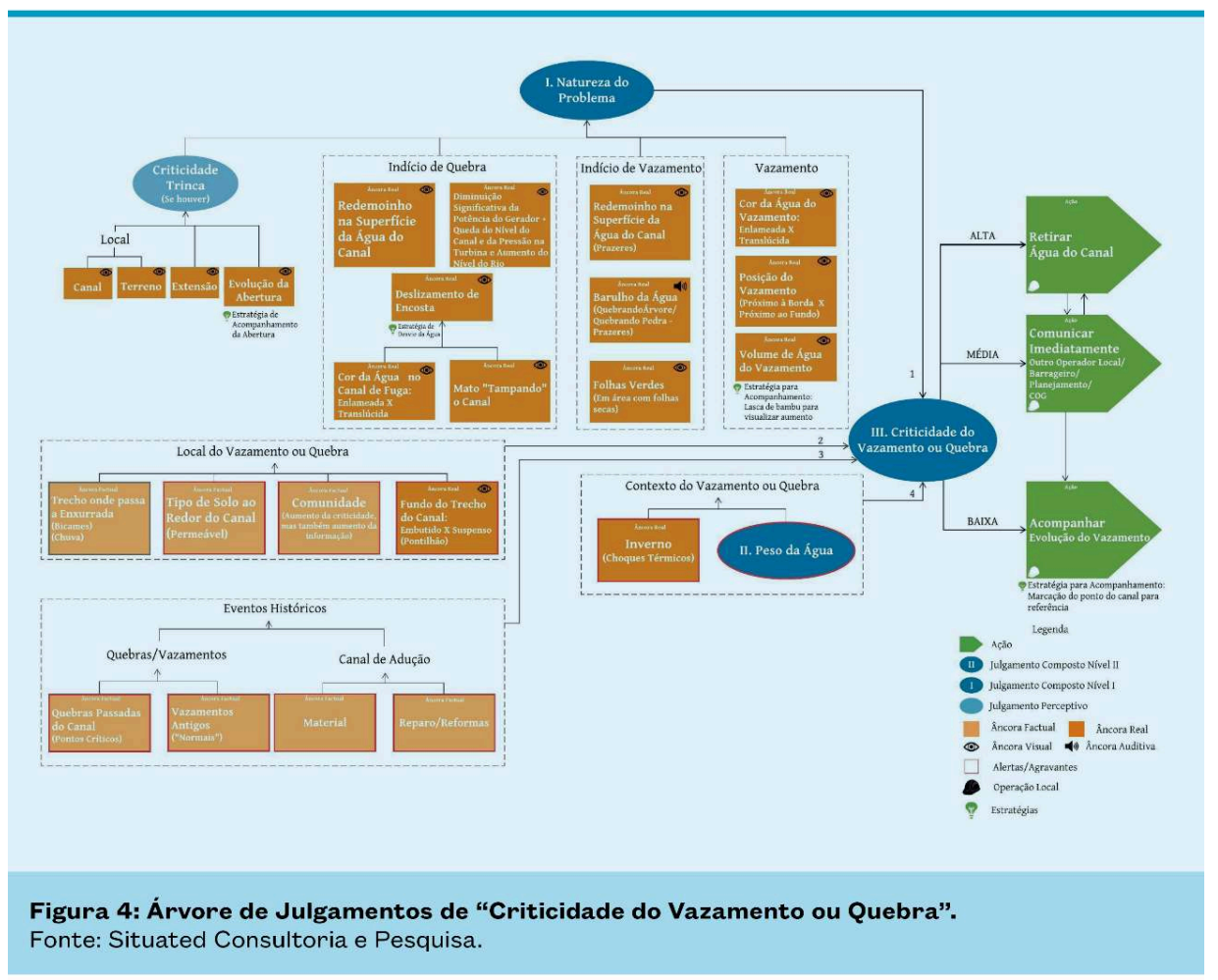

Figura 4 : Árvore de julgamentos de «Criticidade do Vazamento ou Quebra ». Fonte : Situated Consultoria e Pesquisa

Para julgar a criticidade de uma dada condição, o operador julga inicialmente a "natureza do problema" encontrado (vice topo da Figura 4), isto é: O problema é um indício de quebra, é um indício de vazamento ou já é um vazamento? Para identificar cada um desses casos, há âncoras reais associadas a eles. Por exemplo, as âncoras de "indício de quebra" são todas reais e visuais e indicam se a situação encontrada pode ocasionar a ruptura do canal (vide Quadro 2 para a descrição de algumas âncoras verificadas para definir um "indício de quebra"). Além disso, o operador também pode se deparar com trincas, acompanhadas ou não de vazamentos. A criticidade da trinca, quando ela está presente, é um "julgamento perceptivo" simples (baseado exclusivamente em âncoras reais) que auxilia a identificar a natureza do problema e é uma importante base para o operador julgar a criticidade da situação. Já o julgamento da "natureza do problema" é um julgamento composto de nível I, envolvendo as 11 âncoras reais embaixo dele e um julgamento perceptivo simples da "criticidade trinca" (se houver). 
Quadro 2 : Âncoras reais de «Indício de Quebra »

\begin{tabular}{|c|c|}
\hline Âncora & Descrição \\
\hline $\begin{array}{l}\text { Redemoinho na superfície } \\
\text { da água do canal }\end{array}$ & $\begin{array}{l}\text { Redemoinhos indicam um grande vazamento no fundo do canal, pois } \\
\text { movimentam um grande volume de água. }\end{array}$ \\
\hline Deslizamento de encosta: & $\begin{array}{l}\text { O deslizamento de encosta pode trazer impactos graves para a } \\
\text { estrutura do canal. No caso da usina } 3 \text {, onde o solo ao redor do canal } \\
\text { é rochoso, os deslizamentos, ainda que mais raros, podem ser mais } \\
\text { graves, pois demandam intervenções mais demoradas para retirar } \\
\text { o material do canal. O deslizamento pode ser identificado de duas } \\
\text { formas: na usina, se a água no canal de fuga fica enlameada; e no } \\
\text { próprio canal, com o mato começando a "tampar" parte das laterais } \\
\text { ou já com o abatimento de material nas encostas. }\end{array}$ \\
\hline $\begin{array}{l}\text { (1) Cor da água no canal } \\
\text { de fuga }\end{array}$ & $\begin{array}{l}\text { Quando ocorre deslizamento de encosta e grande parte do material } \\
\text { entra no canal, a água no canal de fuga na usina pode ficar enlameada, } \\
\text { indicando a presença de terra. Esta diferenciação é mais comum na } \\
\text { época de seca, em que a água fica mais limpa. No período chuvoso, } \\
\text { como a água já é mais amarronzada, pode haver maior dificuldade na } \\
\text { visualização desta âncora. }\end{array}$ \\
\hline $\begin{array}{l}\text { (2) Mato "tampando" o } \\
\text { canal }\end{array}$ & $\begin{array}{l}\text { Ao percorrer a extensão do canal, os operadores identificam se há a } \\
\text { presença de mato invadindo as laterais do canal, começando, inclusive, } \\
\text { a "tampar" partes da estrutura. Esta âncora é indício de que está } \\
\text { começando um deslizamento de encosta naquele ponto. }\end{array}$ \\
\hline & Indício de Quebra". \\
\hline
\end{tabular}

Quadro 2 : Âncoras reais de «Indício de Quebra »

43 Outro conjunto que dá bases para julgar a criticidade de um vazamento ou quebra é o "local do vazamento ou quebra". Nessa situação, há âncoras factuais e reais (por exemplo, fundo do trecho e tipo de solo) que potencializam as chances de ocorrerem vazamentos e quebras, e outras (por exemplo, a existência de comunidades próximas) que agravam a situação. A descrição das âncoras do "Local do Vazamento ou Quebra" pode ser vista no Quadro 3. 
Quadro 3 : Âncora do « Local do Vazamento ou Quebra »

\begin{tabular}{|c|c|}
\hline Âncora & Descrição \\
\hline $\begin{array}{l}\text { Trecho onde passa a } \\
\text { enxurrada (Bicames) } \\
\text { (Chuva) }\end{array}$ & $\begin{array}{l}\text { Nas inspeções realizadas no periodo chuvoso, a água está presente } \\
\text { em todo o solo ao redor do canal e pode formar enxurradas durante a } \\
\text { chuva. Os operadores conseguem diferenciar se a água é proveniente de } \\
\text { vazamento ou da chuva porque já conhecem os trechos onde a enxurrada } \\
\text { naturalmente passa ou onde há bicames (pequenos vertedouros de } \\
\text { escape). Assim, eles já sabem onde esperar maior volume de água, por ser } \\
\text { passagem da chuva, e onde não deveria estar havendo enxurradas. Trata- } \\
\text { se, portanto, de uma âncora factual. }\end{array}$ \\
\hline $\begin{array}{l}\text { Tipo de solo ao redor } \\
\text { do canal (Permeável) }\end{array}$ & $\begin{array}{l}\text { Quanto mais permeável o solo ao redor do canal, maior as chances de } \\
\text { vazamentos e quebras. Trata-se, portanto, de uma âncora factual. }\end{array}$ \\
\hline Comunidade & $\begin{array}{l}\text { A presença de comunidades próximas ao canal aumenta a criticidade de } \\
\text { um vazamento ou quebra devido ao maior risco de acidentes e impactos } \\
\text { para o trânsito local. Trata-se, portanto, de uma âncora factual, pois o } \\
\text { operador sabe que ali há uma comunidade, sem que necessariamente a } \\
\text { esteja vendo. }\end{array}$ \\
\hline $\begin{array}{l}\text { Fundo do trecho do } \\
\text { canal Embutido X } \\
\text { Suspenso (Pontilhão) }\end{array}$ & $\begin{array}{l}\text { Trechos do canal suspensos, isto é, os chamados "pontilhões", possuem } \\
\text { uma estrutura com maior resistência, pois a base é feita de aço e } \\
\text { concreto. Assim, trechos embutidos, em que a base não é visivel, possuem } \\
\text { estrutura menos resistente e com maior probabilidade de quebras e de } \\
\text { ocorrência de vazamentos. Trata-se, portanto, de uma âncora real, pois } \\
\text { ele vê qual é a estrutura olhando diretamente no canal. }\end{array}$ \\
\hline Q & al do Vaz \\
\hline
\end{tabular}

Quadro 3 : Âncora do « Local do Vazamento ou Quebra »

44 Já nos "eventos históricos", terceiro ponto que contribui para o "julgamento de criticidade de vazamento ou quebra", todas as âncoras são factuais e se referem aos pontos que já apresentaram quebras ou vazamentos e aos aspectos do canal e acontecimentos que impactaram a sua estrutura e, consequentemente, a sua resistência atual. Essas âncoras impactam a natureza e a criticidade dos problemas identificados no momento, além de aumentar a atenção do operador de campo, durante a inspeção, para os pontos que já apresentaram ocorrências no passado.

Por fim, no "contexto", se é uma época de inverno, espera-se que ocorram diferenças altas de temperatura entre o dia e a noite, podendo levar a choques térmicos que agravam a situação de possíveis trincas. Ademais o julgamento do "peso da água", que traduz um sentimento do tanto de água que está no canal ou por vir, pode piorar ou atenuar o julgamento de criticidade em questão. Note-se o julgamento perceptivo composto do "peso da água" é de nível dois, o que significa que ele possui ao menos um julgamento composto de nível um abaixo dele, além de âncoras e/ou julgamentos perceptuais simples. Tais elementos não foram incluídos na Figura 4 por questão de espaço, mas podem ser vistos na Figura 5.

O resultado do "julgamento de criticidade de criticidade ou quebra" é o operador ser solicitado a tomar uma das ações colocadas na Figura 4, representadas pelas setas "largas" verdes. Foram observadas três ações principais:

i. Alta criticidade requer uma ação urgente para retirar imediatamente a água do canal;

ii. Quando se trata de uma criticidade média, outros operadores são comunicados antes de se decidir o que fazer; 
iii. A baixa criticidade, de menor urgência, indica a necessidade de acompanhamento da evolução dos sinais ao longo dos dias.

47 Os operadores se valem também das experiências dos colegas para auxiliar na análise, convocando a manutenção e/ou outros operadores para irem até o local, de modo a tomarem uma decisão coletivamente. A discussão coletiva para definir como agir permite que cada um exponha os pontos críticos identificados e suas percepções, ou seja, somam-se as experiências individuais para tomar a decisão.

Para evitar repetição, não iremos apresentar uma descrição pormenorizada de todas as âncoras, julgamentos e ações da Árvore. O importante é observar que todos os pontos foram encontrados acompanhando as inspeções junto aos operadores, fotografando o que eles consideravam importantes para posterior autoconfrontação, permitindo levantar os pontos de atenção para acelerar a aprendizagem dos novatos. Porém, somente a vivência de diferentes situações na prática é que permitirá, de fato, o desenvolvimento dos treinandos para realizarem os julgamentos que levarão à avaliação da criticidade de um vazamento. Quando os operadores locais viram as árvores, eles reconheceram de imediato a utilidade e os limites:

“É tanta coisa que a gente sabe e nem sabia, né?" / "Quem dera se quando eu tivesse entrado aqui tivesse trabalho assim. Eu teria aprendido mais rápido!" / "Ficou muito bom esse trabalho, mas ainda leva um tempo pra um novato aprender isso tudo aqui." (Operador de campo)

\subsection{2. Árvores Sequenciais}

49 As árvores sequenciais têm o mesmo objetivo das árvores de julgamento, mas se diferenciam por apresentar a sequência das ações que devem ser tomadas dentro de uma atividade. Para tal, ela apresenta um item a mais que é o "contexto" que deve ser avaliado antes da ação, de modo que ela seja segura. Assim, ela agrega valor à maneira como os procedimentos operacionais tradicionais tentam formalizar a atividade humana, ao apresentar aspectos do contexto, os julgamentos e âncoras por detrás de cada ação em atividades que demandam que uma sequência seja seguida, como é o caso da partida de Unidade Geradora (UG) mostrada na Figura 5.

Figura 5 : Extrato de Árvore Sequencial de Partida de Unidade Geradora (UG). Fonte : Situated Consultoria e Pesquisa 


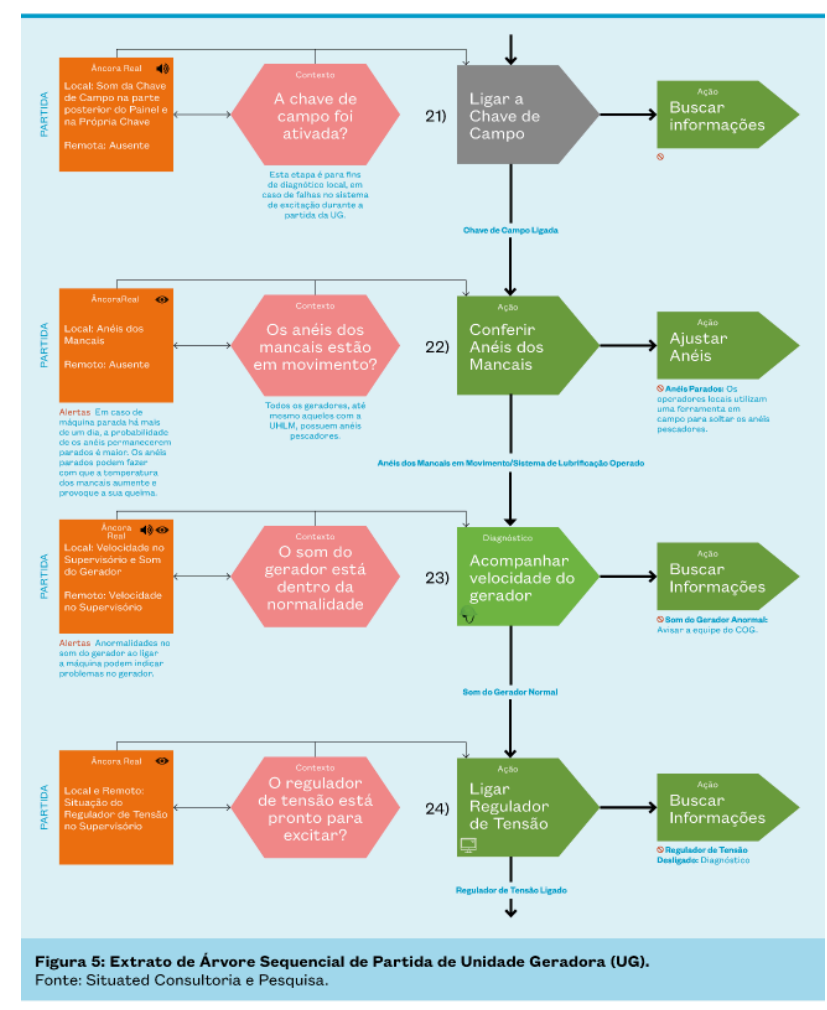

Figura 5 : Extrato de Árvore Sequencial de Partida de Unidade Geradora (UG). Fonte : Situated Consultoria e Pesquisa

Novamente, não iremos detalhar os aspectos técnicos representados na Figura 5. O relevante, no caso das duas árvores, é mostrar como a TCA auxiliou na identificação de todos os itens que precedem ou estão envolvidos na ação dos operadores. Ou seja, a constatação do uso das árvores como objetos intermediários da formação, por meio da sistematização dos "pontos de atenção", que são julgamentos tácitos para os experientes, juntamente com as suas âncoras, mas que, uma vez formalizados, aceleram o aprendizado dos novatos.

51 A aceleração da curva de aprendizado dos operadores dá-se tanto ao aprimorar as interações entre experientes e novatos como ao fornecer o "caminho das pedras" para os novatos se desenvolverem e acompanharem o seu desenvolvimento de uma forma objetiva. Nesse sentido, a definição dos níveis de julgamento também auxilia o planejamento e acompanhamento da progressão do aprendizado, iniciando pelos julgamentos perceptivos simples e depois seguindo para os julgamentos compostos de primeiro nível, segundo nível e assim por diante.

Adicionalmente, verificou-se que as duas árvores também geraram um aprendizado entre os operadores experientes. Isso porque muito do que cada um deles fazia de uma maneira tácita ou sem se dar conta, acabou aparecendo nas árvores em si, nas discussões conjuntas para o seu aprimoramento ou quando esses iam explica-las aos novatos. Com isso, houve uma inesperada troca de experiencias entre eles, que foi além da demanda inicial da empresa, mas reforçou a contribuição que essa formalização, mesmo que limitada, pode trazer para a formação de todos os operadores.

Para se ter uma ideia da extensão e profundidade da análise feita, durante os 10 meses de trabalho, foram analisadas 19 atividades, nas quais foram identificados 99 julgamentos tácitos, alguns deles presentes em mais de uma das 6 árvores de 
julgamento e 13 árvores sequenciais geradas. Dentro os julgamentos tácitos, 41 eram julgamentos perceptuais simples e 58 eram compostos (12 desses antecipatórios), indo até nível 5. Embaixo deles, foram identificadas 347 âncoras, sendo 262 âncoras reais, 69 âncoras factuais e 16 âncoras vividas.

\subsection{Concepção: Modelo Analítico para Automação Antropocêntrica e Apropriável}

Outro produto desenvolvido foi um modelo analítico para viabilizar um projeto de automação que fosse futuramente passível de apropriação pelos operadores e que tivesse as ações deles como centrais no processo de concepção. Isso exigiu verificar se os operadores remotos possuíam (ou não) as mesmas âncoras que estavam disponíveis para a operação local. Tal análise levou a um conjunto de recomendações baseados na "transferência de âncoras" levantadas junto à operação local para apoiar operação remota. Com isso garantia-se que: (1) os operadores remotos teriam todas as âncoras para realizar os julgamentos necessários; e (2) fossem evitadas evitar "caixas pretas" na automação das plantas e no sistema informatizado de controle (sistema supervisório) que dificultassem os ajustes que ainda deveriam ser feitos pelos operadores de campo. Uma das situações analisadas foi o ajuste da energia gerada.

O "Ajuste Fino" é a ação de aumentar ou diminuir a potência das Unidades Geradoras, alterando a carga dessas. A partir da programação de geração, repassada ao operador local pela equipe de planejamento hidroenergético, o ajuste fino permite o cumprimento mais próximo da meta repassada, dentro dos limites operacionais da usina no momento, e de modo a manter a operação mais estável ao longo do tempo - ou seja, com o objetivo de fazer uma alteração que não exija outro ajuste no curto prazo.

Olhando de fora, o comportamento observável do operador consiste somente em, manualmente, abrir ou fechar uma válvula da UG, dentro da PCH (Figura 6). No entanto, para realizar essa ação, o operador considera vários fatores: (i) a economia e melhor uso da água, gerindo a quantidade de água disponível para a geração naquele momento e de acordo com o planejamento recebido (que leva em conta tanto a geração dia como a mensal e a anual); (ii) um melhor aproveitamento possível do equipamento, ou seja, o quanto consegue aproveitar de cada unidade geradora em cada usina, considerando suas especificidades, limites e desempenhos; (iii) a proteção dos ativos da empresa, preservando as máquinas e a segurança das comunidades no entorno das usinas contra quebras dos canais. 
Figura 6 : O Ajuste Fino como «Comportamento Observavél ». Fonte : Situated Consultoria e Pesquisa

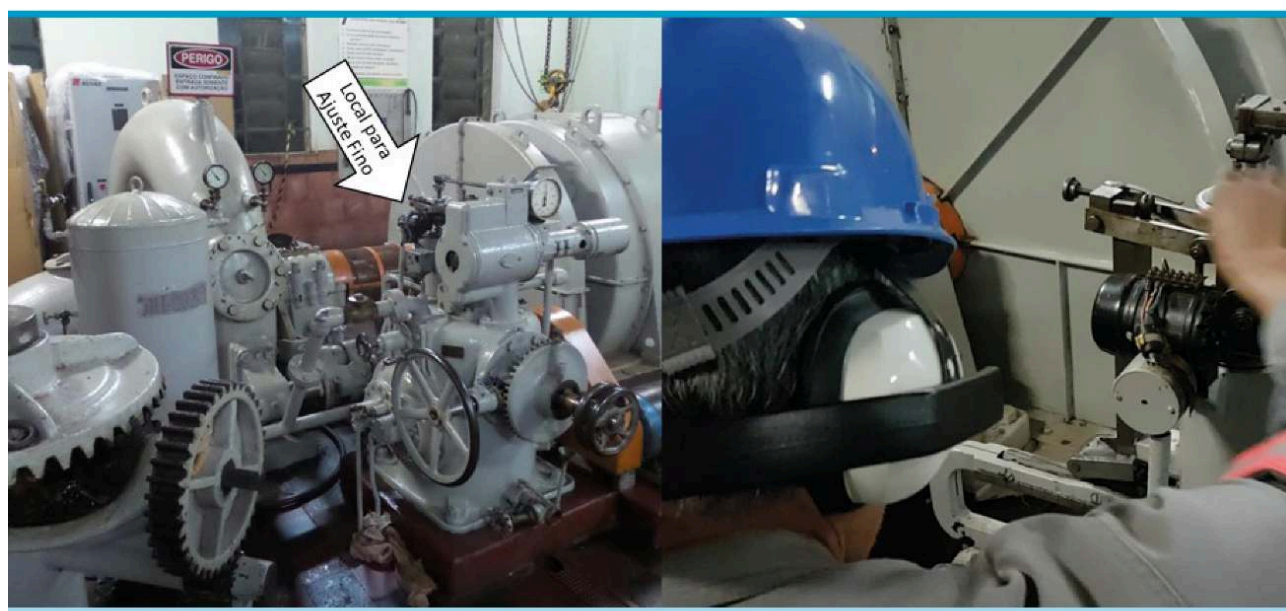

Figura 6: O Ajuste Fino como "Comportamento Observável". Fonte: Situated Consultoria e Pesquisa.

Figura 6 : O Ajuste Fino como « Comportamento Observavél ». Fonte : Situated Consultoria e Pesquisa

57 A Árvore indica, através de quatro quadrantes cinzas, em qual das áreas se encontram os julgamentos e âncoras para realizar essa ação (Figura 7): barragem, canal, usina ou subestação. Além da indicação da localização, os julgamentos e âncoras estão representados de acordo com a sua temporalidade (seta preta no alto da árvore), ou seja, se estão relacionadas: ao histórico do operador (sua experiência), passado recente (até semanas antes), presente e futuro (projeções/antecipações que o operador faz para aquela ação). 
Figura 7 : Indicação da Localização e Temporalidade das Âncoras e Julgamentos. Fonte : Situated Consultoria e Pesquisa

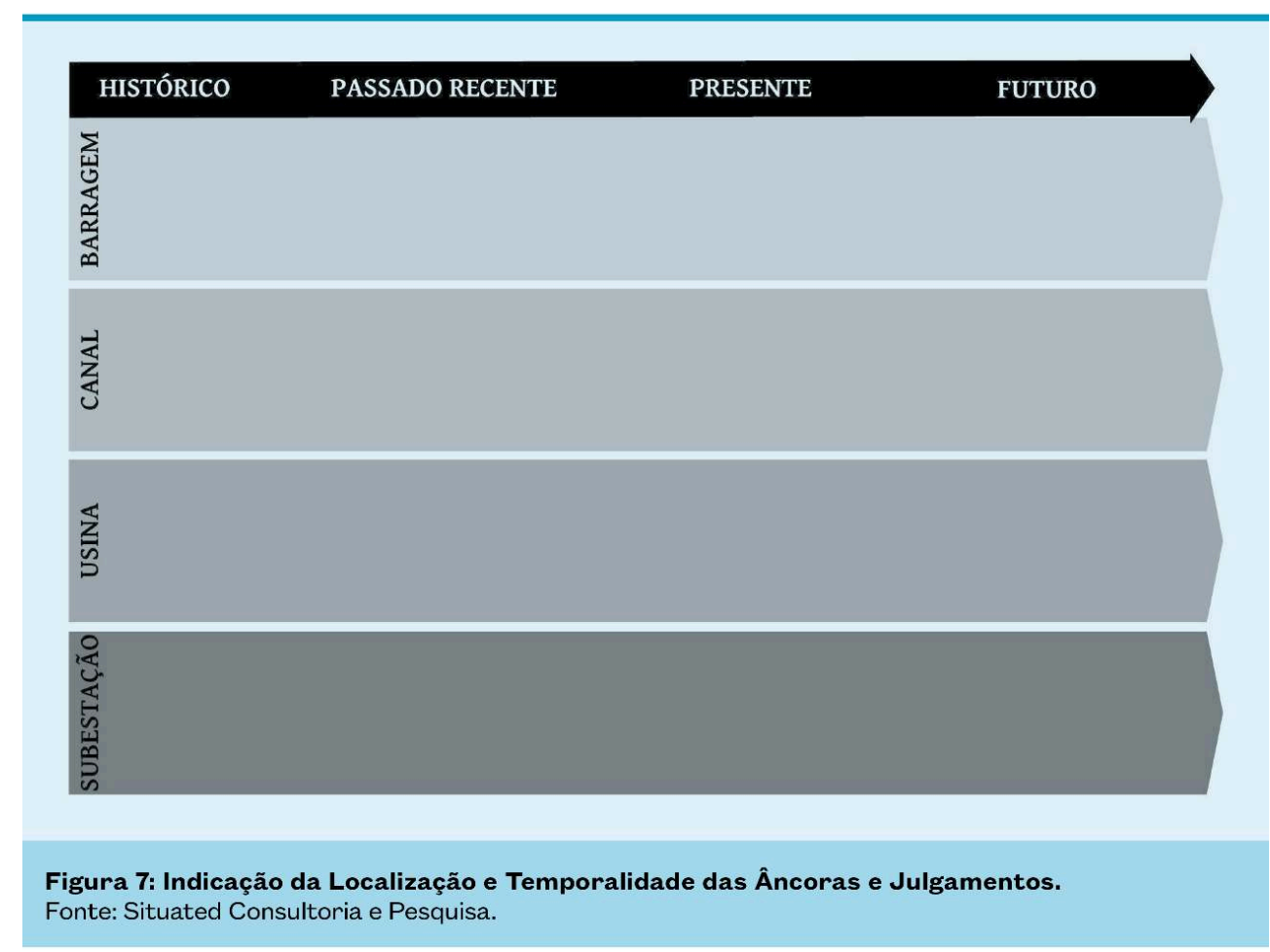

Figura 7 : Indicação da Localização e Temporalidade das Âncoras e Julgamentos. Fonte : Situated Consultoria e Pesquisa

Para realizar a ação de ajuste fino (em verde), o operador local, na usina, faz o julgamento antecipatório (em azul) do tempo de reação e de estabilidade na geração (Figura 8). Ou seja, ele faz duas antecipações: (i) do tempo necessário de resposta ao ajuste para aquela situação; e (ii) do tempo de estabilidade do ajuste, isto é, por quanto tempo aquele ajuste será suficiente para garantir a geração, sem a necessidade de ser feito um novo ajuste no curto prazo. 
Figura 8 : Julgamento antecipatório do tempo de reação e de estabilidade na geração. Fonte : Situated Consultoria e Pesquisa

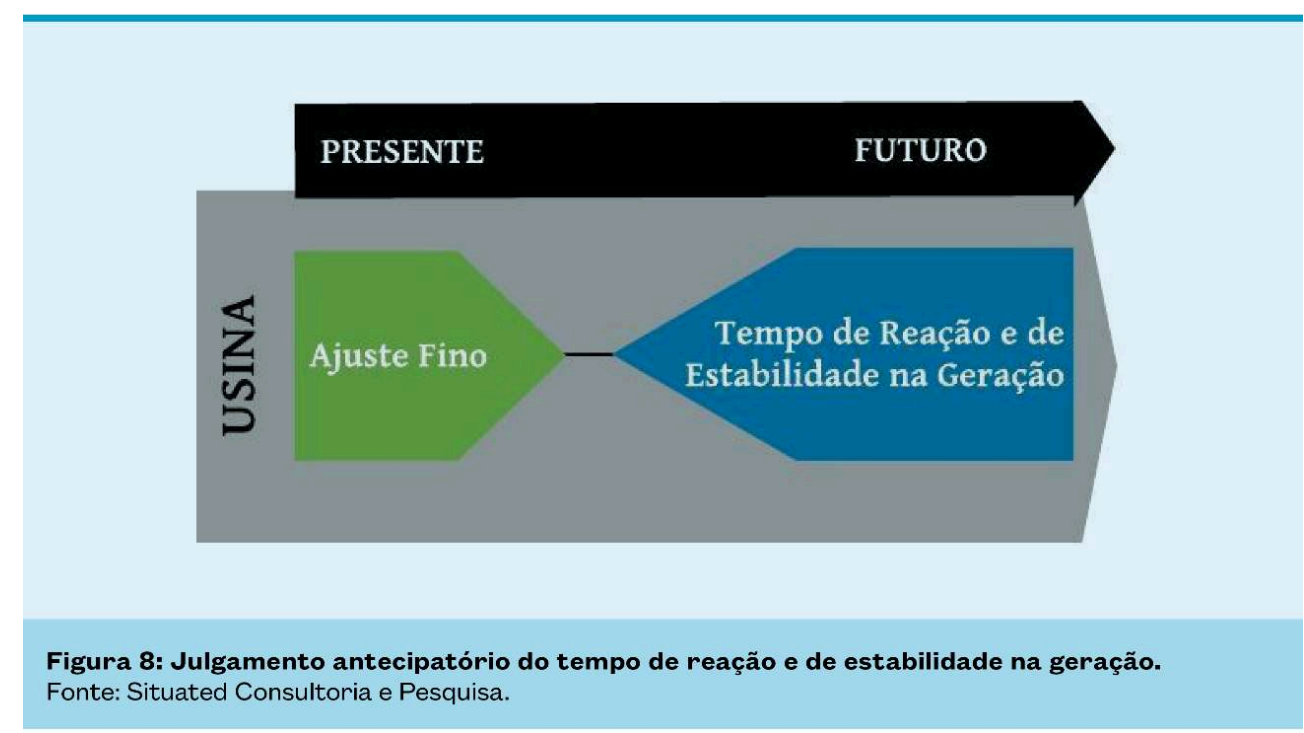

Figura 8 : Julgamento antecipatório do tempo de reação e de estabilidade na geração. Fonte :

Situated Consultoria e Pesquisa

Esse julgamento antecipatório é de alta complexidade e está relacionado a uma antecipação (futuro), que, para ser feita, é necessário realizar dois julgamentos compostos no momento do ajuste (presente). São eles: o de "Sentir o Canal" e o de "Dominar a Máquina". A Figura 9 mostra a Árvore de Julgamentos do Ajuste Fino, em que o importante é a visualização de como as âncoras e julgamentos estão distribuídos ao longo da temporalidade do curso da ação de ajustar a geração, e a experiência do operador é demonstrada nos diferentes locais onde ele visualiza e percebe as âncoras, seja no passado ou no presente. A Árvore demonstra que para uma ação realizada no presente, o passado está de maneira dinâmica nesta ação, por meio da instância de referencial, aqui denominada "âncoras factuais" e "âncoras vividas". 
Figura 9 : Árvore de Julgamentos « Ajuste Fino » : O Comportamento do Ponto de Vista do Operado. Fonte : Situated Consultoria e Pesquisa

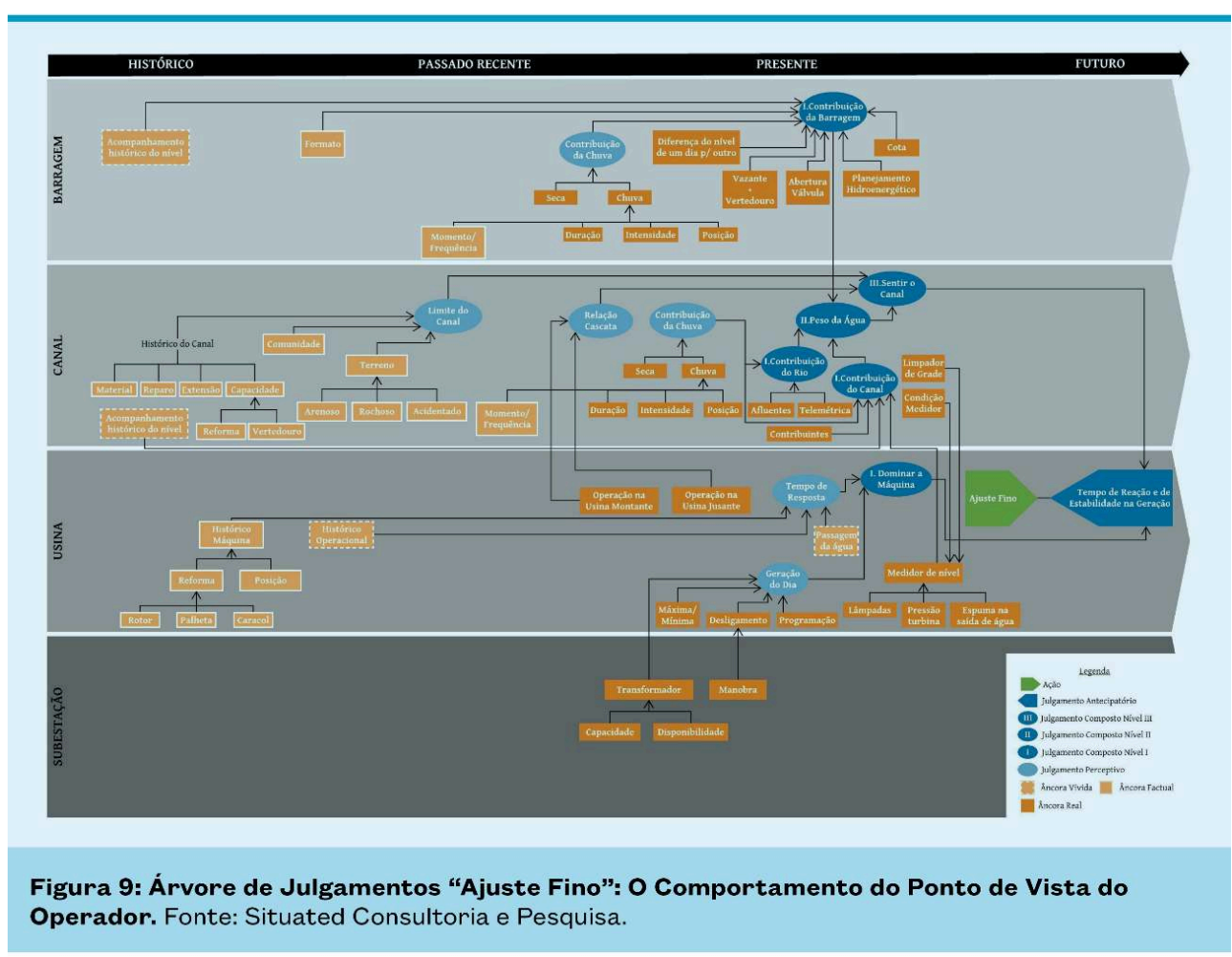

Figura 9 : Árvore de Julgamentos «Ajuste Fino » : O Comportamento do Ponto de Vista do Operado. Fonte : Situated Consultoria e Pesquisa

60 Um fato comum no início da operação remota era que os operadores distantes realizavam "ajustes grossos" e logo o operador local percebia e identificava dentro de quanto tempo ele teria que mexer novamente na potência do gerador. Essa situação mostra como uma atividade que, do ponto de vista do observador externo, se apresenta com um comportamento observável "simples" (Figura 6) é, na verdade, complexa e entremeada pelas diferentes temporalidades da ação, quando analisada do ponto de vista do operador (Figura 9): (i) passado, com a experiência vivida demonstrando pontualmente o que ele vivenciou e que é importante para aquela ação; (ii) presente, apresentando o que ele percebe no mundo naquele momento para agir; e (iii) futuro com as antecipações necessárias para que ele aja de acordo com "onde se quer chegar".

61 Feita essa construção e sistematização das âncoras e seus locais, passou-se para a análise de quais âncoras reais o operador local percebe (visuais, auditivas, olfativas etc.) em cada ação e que, por sua vez, lhe permite desenvolver os "backgrounds vividos" incorporados (âncoras vividas) e a habilidade de realizar julgamentos simples e compostos de acordo com a situação. Essa análise permite observar como essas âncoras estão disponíveis às diferentes equipes (local e remota). Quando estão presentes no Supervisório, significa que estão acessíveis ao operador remoto, mas quando estão presentes somente no "localíssimo", ou seja, no próprio equipamento ou na região das usinas, consideramos que estão inacessíveis remotamente.

62 Essa análise é importante para verificar as ações que podem ser realizadas por cada uma das equipes (local e remota). Sugere-se que, para aumentar a eficiência no desempenho da atividade, a segurança e a proteção dos ativos do complexo energético, 
a atividade seja realizada por determinada equipe somente quando estão disponíveis todas as âncoras para executar as ações. Assim, criou-se uma classificação das âncoras após a automação com o tipo de operação demandada em cada caso, ou seja, se é somente local, somente remota ou em co-operação (operação remota + local). o Modelo Analítico foi construído para dar embasamento técnico à implementação da cooperação, auxiliando a elaboração ou o refinamento da Matriz de Responsabilidades para cada atividade e nas decisões coletivas. Além disso, ele permitiu refinar a automação já realizada e guiar futuros projetos a serem realizados em usinas em cascata.

Um sistema automatizado pode ter, como parte de seus algoritmos, regras de desarme ou de alarme, por exemplo, caso o processo atinja uma determinada temperatura ou o nível de material em um tanque chegue a uma determinada altura. Porém, a habilidade de realizar julgamentos antecipatórios pelos operadores de PCHs é uma parte relevante de sua atividade e isso só é possível porque a percepção humana traz consigo o sentido da situação. A percepção de risco e de urgência, por exemplo, só aparece para quem consegue antecipar as consequências se algo der errado. A automação, somada aos padrões e procedimentos operacionais, tenta sistematizar aspectos da experiência humana, mas será sempre dependente dela. Isso não implica que uma automação não possa substituir alguns operadores de campo por um só operador remoto ou que a automação não funcione. Isso só mostra que o conhecimento tácito não pode ser totalmente formalizado e aquilo que é produzido com a "formalização" (procedimentos, regras, algoritmos, automatismos, etc.) depende do conhecimento tácito de profissionais experientes para poder funcionar bem ou ser bem utilizado. 0 Modelo Analítico criado analisa cada uma das âncoras de uma atividade vis-à-vis o sistema automatizado e as classifica em: mantidas, não disponibilizadas, embutidas e substituídas (pelo sistema), como demonstrado na Figura 10. Apresentamos a seguir cada uma dessas categorias. 


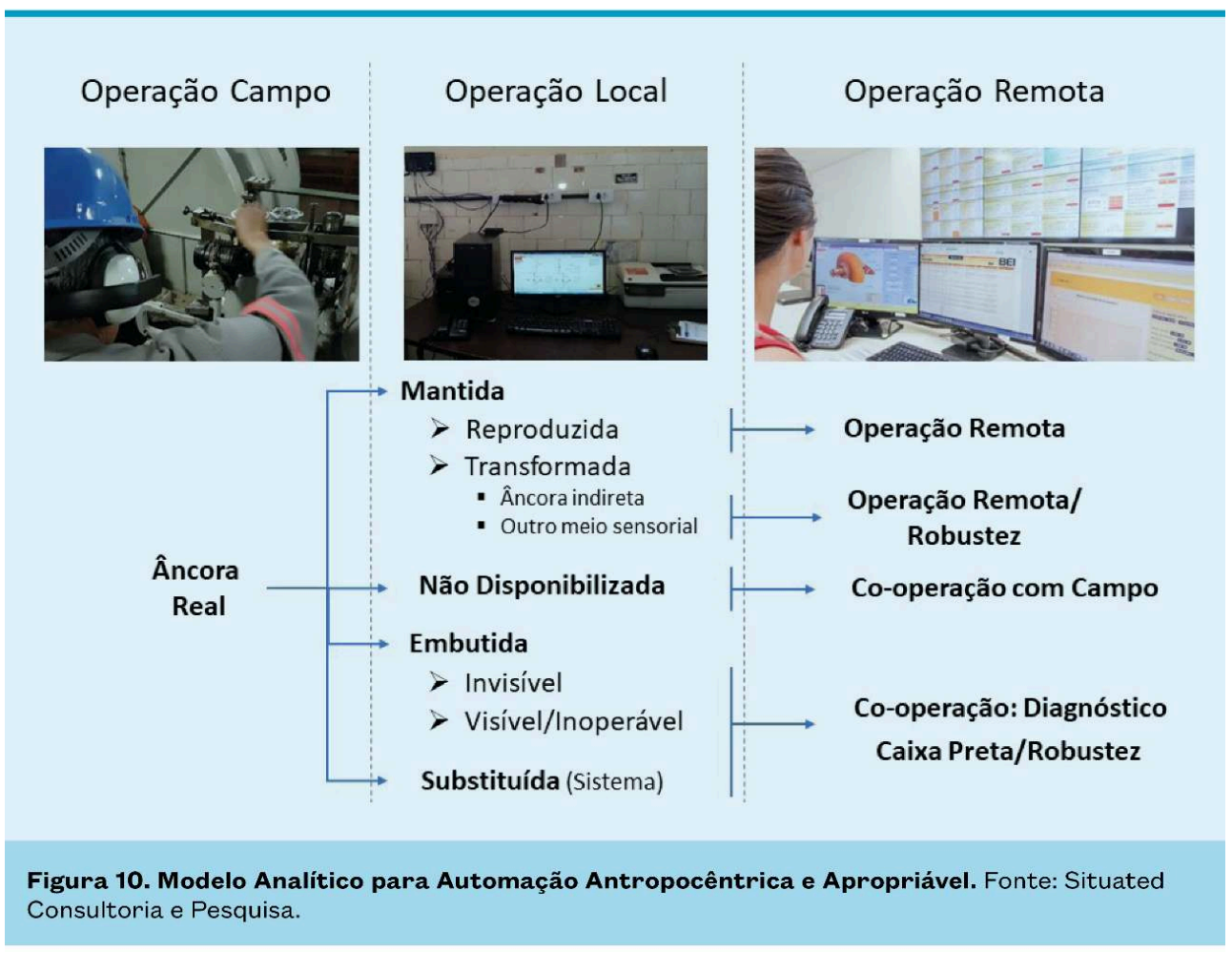

Figura 10 : Modelo Analítico para Automoção Antropocêntrica e Apropriável. Fonte : Situated Consultoria e Pesquisa

\subsection{1. Âncoras mantidas}

Quando as âncoras reais percebidas pelo operador local para executar uma ação estão disponíveis ao operador remoto, seja através do sistema informatizado de controle (ou sistema supervisório) ou por câmeras, consideramos que elas estão MANTIDAS após a automação. É possível, assim, criar as condições para que o operador remoto desenvolva as habilidades necessárias para dar significado ao que percebe, dentro dos diferentes contextos. Essas âncoras podem estar mantidas de duas formas:

1. REPRODUZIDAS: quando as âncoras estão acessíveis da mesma forma aos operadores locais e remotos, dizemos que ela foi mantida e reproduzida. Um exemplo é quando uma câmera é colocada no vertedouro, permitindo a visualização da vazão da água naquele momento.

2. TRANSFORMADAS: quando as âncoras estão acessíveis ao operador remoto, mas houve um processo de tradução para ser disponibilizada no Supervisório, dizemos que ela foi mantida e transformada. Tal transformação pode-se dar por meio de uma âncora "indireta" que utilize o mesmo ou outro meio sensorial. Um exemplo de manutenção do meio sensorial é a verificação se o disjuntor está ligado ou desligado, que era feita visualmente no próprio equipamento e que passou a ser feita, também visualmente, na tela do Supervisório. Já um exemplo de mudança sensorial é verificar a velocidade da UG, que antes percebida pelo som do gerador e foi transformada em uma medida de rotações por minuto (rpm).

Em ambas as formas da âncora mantida, a ação pode ser realizada remotamente, necessitando da co-operação somente em casos de diagnóstico corretivo e para verificar, realmente, se a transformações realizadas realmente geraram uma operação 
remota robusta, ou seja, se os dados reproduzidos e transformados são confiáveis ou se é necessária introduzir uma redundância para validar um indicador.

\subsection{2. Âncoras não disponibilizadas}

Quando as âncoras necessárias para se tomar uma decisão e realizar uma ação estão disponíveis somente para a operação local, ou seja, quando não foram inseridas no sistema do Supervisório ou por meio de câmeras, dizemos que elas são âncoras NÃO DISPONIBILIZADAS à operação remota. Um exemplo é a chave seccionadora, em que não há dados no Supervisório se ela se encontra aberta ou fechada e a ação somente é realizada localmente. Desse modo, quando se trata de uma âncora não disponibilizada, a ação só pode ser realizada localmente para aumentar a segurança e a proteção dos ativos.

\subsection{3. Âncoras embutidas}

67 Com a automação, algumas operações que antes eram realizadas com a ação direta do operador foram transformadas em operações realizadas pelo próprio sistema. Desse modo, elas ainda existem, como a abertura automática da válvula borboleta, mas é o sistema que realiza a conferência e posterior atuação sobre ela. Dizemos, assim, que essas âncoras são EMBUTIDAS, já que estão presentes, mas submetidas ao controle feito pelo sistema automatizado. Essas âncoras podem estar presentes de duas formas:

1. INVISÍVEL: algumas âncoras não podem ser percebidas após a automação, embora elas sejam conferidas pelo sistema automatizado.

2. VISÍVEL/INOPERÁVEL: algumas âncoras permanecem disponíveis para os operadores após a automação, embora a ação seja realizada pelo sistema. Assim, eles conseguem percebê-las no momento, mas não conseguem agir sobre ela. É o caso, por exemplo, da conferência feita dos parâmetros de frequência, tensão e corrente para ligar manualmente o disjuntor. Hoje os valores desses três parâmetros estão disponíveis ao operador, mas o disjuntor é operado pelo sistema.

Em ambas as formas de âncora embutida, sugere-se verificar a robustez da automação na conferência e na execução da operação. No caso da âncora embutida e invisível, essa robustez se faz ainda mais necessária, pois existe uma caixa preta para o diagnóstico, ou seja, o operador não tem acesso a dados a serem percebidos e analisados em uma ocorrência de falha. Já no caso da âncora embutida visível/inoperável, o diagnóstico corretivo é facilitado, já que o operador possui os dados/sinais a serem percebidos e analisados após a ocorrência de falha. Além do diagnóstico corretivo, quando as âncoras estão disponíveis para a operação, cria-se condições necessárias para desenvolver a habilidade de antecipação e atuar de modo a evitar a ocorrência de falhas.

\subsection{4. Âncoras substituídas (sistema)}

Com a automação, algumas operações que antes eram realizadas com a ação direta do operador, por exemplo, ligar a chave de sincronismo, foram excluídas por completo ou transformadas em outras operações no sistema automatizado, completamente distintas das originais. Assim, dizemos que as âncoras foram SUBSTITUÍDAS e não estão mais acessíveis ao operador local e remoto. Nesse caso, temos uma caixa preta para a operação, já que o operador não possui dados/sinais para serem percebidos e 
analisados durante a atividade. Sugere-se verificar a robustez da automação na execução da operação.

Para facilitar a classificação das âncoras, uma planilha foi criada (Quadro 4) com as âncoras de uma atividade realizada pelos operadores locais, mostrando também as potenciais consequências, caso uma atividade seja realizada sem a disponibilização de algumas âncoras importantes para a ação. Isso levou a sugestões de melhorias no sistema automatizado, para que esse se tornasse mais aderente ao trabalho dos operadores. Exemplos foram a inclusão e melhoria nas âncoras para os operadores remotos, de modo a transformar algumas "caixas pretas" do sistema automatizado em “caixas de vidro" (Lave \& Wenger, 1991/2009, p. 102), auxiliando o entendimento da lógica de certos automatismos e de sua supervisão pelos operadores. Ou seja, por meio de alterações das condições técnicas para uma ação mais eficiente e segura, desenhouse o caminho para a implementação de um sistema mais antropocêntrico e apropriável, pois que mais aderente e transparente.

Quadro 4 : Modelo Analítico de Co-Operação Exemplo Partida de entidade geradora - Árvore 14

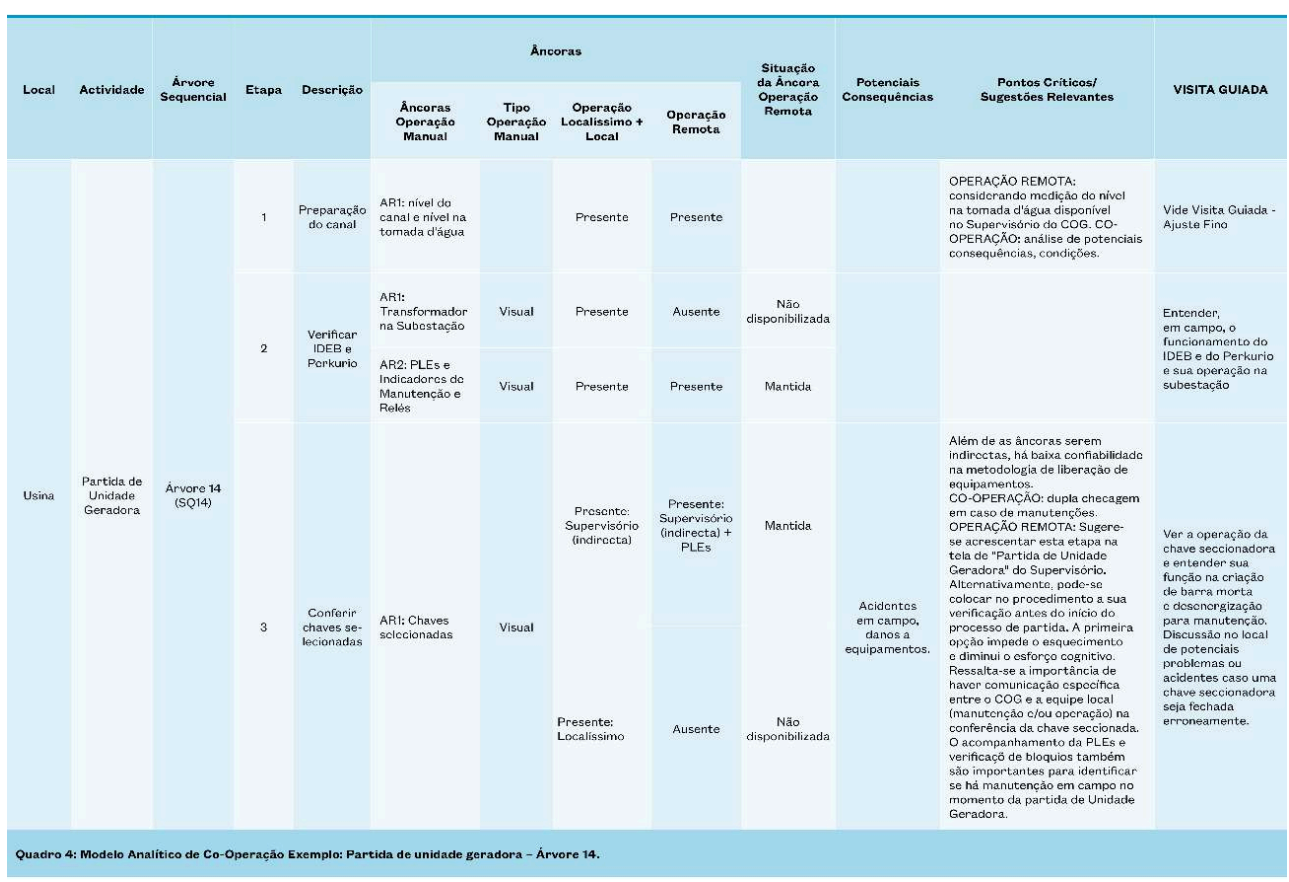

Quadro 4 : Modelo Analítico de Co-Operação Exemplo Partida de entidade geradora - Árvore 14

\subsection{Co-operação H-H-M: Modelo Analítico: Operação Local versus Operação Remota}

Um terceiro conjunto de proposições diz respeito à organização e divisão de trabalho entre operadores locais e remotos. Isso exigiu a formação dos operadores remotos, que tratamos neste item e não junto com a formação de operadores de campo, porque essa formação foi base para instituir uma nova divisão de tarefas e iniciar um processo de cooperação entre operadores de campo e operadores remotos. Trata-se, na verdade, de uma co-operação, pois certas decisões e ajustes passaram a ser compartilhados entre essas duas categorias, aumentando o escopo de tarefas e a autonomia dos operadores de campo. Certas decisões passaram a ser tomadas coletivamente, outras deixadas aos 
operadores de campo que podiam avaliar e decidir melhor o que fazer e no tempo certo, outras sendo feitas exclusivamente elos operadores remotos. Por exemplo, na Figura 5, há ações nas árvores sequenciais que cabem à operação local (assinalada por um "capacete") ou à operação remota (assinalada por uma "tela"). Também há ações, não apresentadas nessa figura, onde aparecem os dois símbolos, demonstrando a necessidade de uma operação conjunta, o que denominamos de co-operação.

o "Modelo Analítico Operação Local x Remota", em conjunto com o anterior, tem como objetivo principal criar as condições para se analisar a automação - já existente ou futura - de uma determinada atividade. Ou seja, para verificar se a automação realizada (ou a ser realizada) está aderente à atividade executada localmente. Com isso, é possível: (i) aprimorar sistemas automatizados já em uso; (ii) conceber sistemas de automação mais aderentes (evitando retrabalho posterior) e (iii) identificar as atividades nas quais faz-se necessária uma co-operação entre os operadores remotos e locais, mesmo após finalizado o processo de automação. Essa última análise permite também elaborar uma matriz de responsabilidades divididas entre a operação remota $\mathrm{e}$ a local, dando suporte para um dimensionamento de equipes adequado às necessidades de geração e, ao mesmo tempo, de proteção de ativos - um ponto relevante no dia-a-dia da operação das usinas em cascata.

Após a definição das Matrizes de Responsabilidade, com a alocação das atividades que deveriam ser realizadas pela equipe local, equipe remota ou em co-operação, foram realizadas Visitas Guiadas dos operadores remotos ao complexo das usinas. Elas foram guiadas pelos operadores locais que participaram da construção das árvores, visando a apropriação, em parte, das principais âncoras reais que dão base aos seus julgamentos e ações. Essas visitas operaram transformações significativas nos operadores remotos, que deixaram de assumir uma posição hierárquica em relação aos operadores de campo. Algumas frases dos operadores remotos durante as visitas mostram as mudanças: "O (nosso supervisor) fala, mas eu não tinha ideia da proporção."/"Agora sei o que eles querem dizer"/“Nós nem temos os parâmetros dessas réguas! [sobre réguas físicas]". Por outro lado, os operadores locais após o treinamento dos operadores remotos se preocupam menos e confiam mais nos controladores remotos: "Agora a gente tá até pedindo menos para eles aumentarem a potência pra diminuir a água do canal!"

Um desenvolvimento dessas intervenções que ainda não foi possível fazer é a concepção dos sistemas supervisórios e das interfaces dos sistemas informatizados da sala de controle. Uma descrição mais fina dos processos decisórios envolvidos no "sentir o canal" e outras atividades específicas dos operadores de campo poderiam gerar modelos descritos do curso da ação e orientar a atuação dos operadores remotos bem como a sua formação.

\section{Conclusão}

Por que vemos ainda hoje, em torno da indústria 4.0, repetirem equívocos, como a fábrica sem homens, com a qual os engenheiros sonhavam desde os anos 1950 ?

As promessas da primeira onda da I.A. dos anos 1950 foram amplamente criticadas (Dreyfus, 1984; Collins, 1992; Winograd \& Flores, 1989) e invalidadas pela experiência prática, no entanto sempre reaparecem. Para citar apenas um exemplo, nos anos 1990, encontramos um especialista do MIT, Dertouzos, que retoma o credo, mesmo 
reconhecendo que, após quase 50 anos de tentativas, as tecnologias ainda precisam evoluir: "As máquinas automáticas precisariam ser aperfeiçoadas a fundo para produzir bens e serviços sem ajuda humana." (Dertouzos, 1997, p. 340). Juntamente com a promessa de automatismos sem homens, vem um projeto de sociedade: "Numa sociedade livre do trabalho as pessoas não seriam mais obrigadas a trabalhar para viver" (Idem, p. 341), possibilidade que não se realiza não devido às relações sociais de produção, mas ao consumismo dos indivíduos:

“o tempo para o lazer na verdade diminuiu... Embora nossa produtividade tenha aumentado, e as necessidades básicas estejam satisfeitas, preferimos trabalhar mais ainda, para elevar o nível de vida e comprar produtos de luxo..." (Dertouzos, 1997, p. 341)

“Todos serão capitalistas, pois todos possuirão máquinas e outros bens de capital geradores de lucro." (Id. p. 342)

Repete-se aqui, na visão capitalista neoliberal, a mesma visão que Aristóteles, com outra grandeza, antecipava:

"Se cada instrumento pudesse executar por si mesmo a vontade ou a intenção do agente, como faziam, fala-se, as marionetes de Dedalus ou os tripés de Vulcano, que se vinham por eles mesmos, segundo Homero, aos combates dos deuses, se a lançadeira tecesse sozinha o tecido, se o arco produzisse sozinho, da cítara, os sons desejados, os arquitetos não teriam necessidade de trabalhadores, nem os mestres de escravos". (Aristóteles. 2006, p. 10-11).

Essas utopias tecnológicas retiram sua eterna juventude da dupla ingenuidade dos engenheiros: (i) o racionalismo técnico que sustenta a crença de que uma I.A. seja possível; e (ii) que a tecnologia pode por si só resolver os males sociais - ambas crenças hoje reforçadas pela avassaladora negação social sofrida pelo trabalho diante do avanço da onda neoliberal. Reencontramos, aqui, a questão do caráter antropologicamente constitutivo da técnica adotada em termos bem mais consistentes pela teoria do curso da ação em sua vocação de tornar a concepção ergonômica um instrumento de transformação social. Com nossos exemplos relativamente reduzidos, no sentido de operar transformações locais, mostramos empiricamente o que as descrições da atividade em modelos do curso da ação ou sistematizações de seus elementos pode promover em termos de mudança técnica e mudança de relações sociais integradas.

O projeto inicial da empresa era criar PCHs não-habitadas, operadas apenas remotamente, por técnicos treinados apenas na supervisão dos sistemas informatizados de controle. Ao final, foi possível mostrar que esse modelo não poderia funcionar, sendo adotado um sistema co-operativo, com decisões tomadas de forma colaborativa pelos operadores remotos e operadores de campo. Quanto à presença destes, a automação, quando adquire uma relativa estabilidade, permite reduzir a quantidade de operadores, que não atuam mais de forma dedicada a uma usina, mas a polivalência deve ser desenvolvida de forma mais rigorosa com ajuda das árvores de julgamento. Elas contribuem, assim, não para eliminar os operadores de campo, mas para facilitar o desenvolvimento do saber tácito necessário nos julgamentos situados, tanto em campo 
quanto remotamente. Essa nos parece ser uma demonstração palpável de um aspecto do que pode ser "uma humanidade desejável" (Theureau, 2015a).

\section{BIBLIOGRAFIA}

Aristóteles. (2006). A Política. São Paulo: Martins Fontes.

Assunção, A. A. (1998). De la déficience à la gestion collective du travail. Thèse de Doctorat d'Ergonomie. Paris, EPHE.

Bainbridge, L. (1987). Ironies of automation. In Rasmussen, J., Duncan, K., \& Leplat, J. New technology and human error. (pp. 271-283). New York: John Wiley.

Bijker, W. E., Hugues \& Pinch, T. (1989). The social construction of technological systems. Cambridge: MIT Press.

Böhle, F., \& Milkau, B. (1988). De la manivelle à l'écran. L'évolution de l'expérience sensible des ouvriers lors des changements technologiques. Paris: Eyrolles.

Brödner, P. (1990). Technocentric-Anthropocentric Approaches. In Warner, M., Wobbe, W., \& Brödner, P. New technology and manufacturing management. (pp. 101-111). New York: John Wiley.

Brödner, P. (1993). Anthropocentric production systems. In Salvendy, G., \& Smith, M. (eds). Human-computer interaction. (pp. 74-79). Amsterdam: Elsevier.

Caroly, S. (2012). Gestion collective de situations critiques au guichet en fonction de l'âge. In A. F. Molinié, C. Gaudart, \& V. Pueyo (Eds.), La vie professionnelle: âge, expérience et santé à l'épreuve des conditions de travail. (pp. 223-234). Toulouse: Octarès.

Clot, Y. (2010). Trabalho e poder de agir. Belo Horizonte: Fabrefactum.

Clot, Y., Faïta, D.; Fernandez, G., \& Scheller, L. (2000). Entretiens en autoconfrontation croisée: une méthode en clinique de l'activité. PISTES, 2 (1). http://pistes.revues.org/3833

Collins, H. M. (1992). Experts artificiels. Paris: Seuil.

Corbett, J. M., Rasmussen, L. B., \& Rauner, F. (1991). Crossing the border: the social and enginnering design of computer integrated manfacturing systems. Berlin: Springer-Verlag.

Daniellou. (2007). A ergonomia na condução de projetos de concepção de sistemas de trabalho. F. In Falzon. op cit., p. 303-316.

Dertouzos, M. (1997). o que será? São Paulo: Companhia das Letras.

Dreyfus, H. (1984). Intelligence Artificielle: mythes et limites. Paris: Flammarion.

Duarte, F. M. C., \& Lima, F. P. A. (2012). Anticiper l'activité par les configurations d'usage. @ctivites, 9, 22 - 47.

Ehn, P. (1988). Work-oriented design of computer artifacts. Stockholm: Arbetslivscentrum.

Eijnatten, F. M. (1993). The Paradigm That Changed the Work Place. Assen: Van Gorcum.

Engeström, Y. (1987). Learning by expanding. Helsinki: Orienta-Konsultit. 
Falzon, P. (2013). Ergonomie constructive. Paris: PUF.

Falzon, P. (2007). Ergonomia. São Paulo: Edgard Blucher.

Ferreira, L. L. (2015). Análises do trabalho. Belo Horizonte: Fabrefactum.

Fernandez, G. \& Clot, Y. (2007). Entrevistas en auto-confrontación: un método en clínica de la actividad. Laboreal, 2, (1), 15-19. http://laboreal.up.pt/revista/artigo.php?

id=37t45nSU5471122987296762231

Fernandez, G. (2004). Développement d'un geste technique. Histoire du freinage en Gare du Nord. Thèse de doctorat en psychologie. Paris, CNAM.

Folcher, V. e Rabardel, P. (2007). Homens, artefatos, actividades : perspectiva instrumental. In : Falzon (2007). Op. cit., p. 207-222.

Garrigou, A., Daniellou, F., Carballeda, G., \& Ruaud, S. (1995). Activity analysis in participatory design and analysis of participatory design activity. International Journal of Industrial Ergonomics 15 (1995) 311-327.

Ingold, T. (2001). From the transmission of representations to the education of attention. In H. Whitehouse (Ed.). The Debated Mind: Evolutionary psychology versus ethnography. (pp. 113-153). Oxford: Berg.

Lima, F. P. A., \& Duarte, F. M. C. (2014). Integrando a ergonomia ao projeto de engenharia: especificações ergonômicas e configurações de uso. Gestão \& Produção. 21, 679 - 690.

Lima, F. P. A., Duarte, F. M. C., Resende, A. E., Garrigou, A., \& Carballeda, G. (2015). Où est la maîtrise du projet dans les processus de conception dans les organisations complexes. Anais do $50^{0^{e ̀ m e}}$ Congrès de la SELF Articulation performance et santé dans l'évolution des systèmese de production. (pp 468-475). Paris: SELF. (Vol. 1).

Mackenzie, D., \& Wajcman, J. (Eds.). (1999). The Social Shaping of Technology. Buckingham: Open University Press.

Nardi, B. A. (ed.) (1997). Context and consciousness. Cambridge: MIT Press.

Pinsky, L. (1992). Concevoir pour l'action et la communication. Berne: Peter Lang.

Ribeiro, R. (2013). Remarks on Explicit Knowledge and Expertise Acquisition. Phenomenology and Cognitive Sciences, 12, 431-435.

Ribeiro, R. (2014). The Role of Experience in Perception. Human Studies, 37, 559-581.

Rocha, R., Daniellou, F., \& Mollo, V. (2014). O retorno de experiência e o lugar dos espaços de discussão sobre o trabalho: uma construção possível e eficaz. Trabalho \& Educação, 23(1), 61-74.

Rocha, R. (2015). Do Silêncio organizacional aos espaços de debate sobre o trabalho. In Lima, F., Rabelo, L., Castro, M. Conectando Saberes. (pp. 111-140). Belo Horizonte: Fabrefactum.

Rocha, R., Mollo, V., \& Daniellou, F. (2015). Work debate spaces. Applied Ergonomics, 46(a), 107-114. Simonet, P. (2009). L'examen méthodique d'un geste de métier pour une prévention durable des TMS. PISTES, 11(2). http://pistes.revues.org/2404

Stiegler, B. (2018). La technique et le temps. Paris: Fayard.

Theureau, J. (1992/2004). Le Cours d'Action: Méthode Élémentaire. Toulouse: Octarès.

Theureau, J. (2019). Le Cours d'Action: Économies et activités. Toulouse: Octarès. 
Theureau, J. (2015a). A hipótese da cognição (ação) situada e a tradição da análise do trabalho na ergonomia de língua francesa. In Lima, F., Rabelo, L., Castro, M. (Orgs.). Conectando saberes. (pp. 285 - 313). Belo Horizonte: Fabrefactum,.

Theureau, J. (2015b). Le Cours d'Action: L'énaction et l'expérience. Toulouse: Octarès.

Theureau, J. (2014). o curso da ação: método elementar. Ensaio de antropologia enativa e ergonomia de concepção. Belo Horizonte: Editora Fabrefactum.

Theureau, J. (2009). Le Cours d'Action: Méthode réfléchie. Toulouse: Octarès.

Theureau, J. (2006). Le Cours d'Action: Méthode développée. Toulouse: Octarès.

Theureau, J., \& Jeffroy, F. (Coord). (1994). Ergonomie des situations informatisées. Toulouse: Octarès.

Theureau, J., \& Pinsky, L. (1984). Paradoxe de l'ergonomie de conception et logiciel informatique. Paris: Revue des Conditions de Travail, 9.Reproduzido em Pinsky 91992). Op. cit., p. 247-263.

Trinquet, P. (2010). Trabalho e educação: o método ergológico. Revista HISTEDBR On-line, número especial. $93-113$.

Vinck, D. (2013). Engenheiros no cotidiano. Belo Horizonte: Fabrefactum.

Winograd, T., \& Flores, F. (1989). L'intelligence artificielle en question. Paris: PUF.

Wisner, A. (2004). Questões epistemológicas em Ergonomia e em análise do trabalho. In Daniellou, F. (ed.). A ergonomia em busca de seus princípios debates epistemológicos. (pp. 29 - 56). São Paulo: Edgard Blucher.

\section{NOTAS}

1. Para uma visão geral dessas abordagens de projeto em ergonomia, remetemos o leitor à obra coletiva organizada por Falzon (2007). Em Rabardel, o polo tecnológico é central, mas a teorização parou na noção de esquemas operatórios, inspirada em Piaget, que ainda carece de uma modelização dinâmica para dotar a técnica de características de apropriabilidade como é enfatizado na TCA (ver seção 3).

2. Essa "explicitação" do que é tácito é sempre parcial, pois todo conhecimento tácito, uma vez elicitado, torna-se "reificado" (Ribeiro, 2013, p 431), exigindo, de novo, experiência e habilidades tácitas para o seu uso situado. Assim, os objetos intermediários da formação, nesse caso, as árvores de julgamento e sequenciais, servem para sistematizar "pontos de atenção" para experientes e novatos, auxiliando nas interações ora mencionadas.

3. Corbett, Rasmussen e Rauner (1991, p. 131) concluem o relato dos projetos com notas pessimistas: "Com base em um conhecimento íntimo da empresa para a qual trabalha, um dos engenheiros envolvido em nosso projeto afirmou que 'um outro grande problema é fazer com que a gestão tradicional aceite que indivíduos requerem alto grau de liberdade para que sejam flexíveis'. A nossa experiência de envolver a gestão em empresas inovadoras em direção a um maior grau de CIM centradas no humano confirma que, em regra, a gestão orientada por marketing, devido à sua afinidade intelectual com a economia aplicada, tem mais propensão a impedir qualquer inovação de longo prazo do que os seus pares orientados pela engenharia e pela produção." (Tradução livre).

4. Os autores diferenciam assim "atividade objetivante" e "atividade subjetivante": "Para o problema que nos interessa aqui, é lógico designar uma atividade racional - racional segundo os critérios dominantes - pela expressão de atividade objetivante. Exprime-se assim uma característica fundamental: tal atividade se baseia em conhecimentos objetivos e, por 
conseguinte, em regras universalmente reconhecidas e generalizáveis. (Böhle \& Milkau, 1998, p. 17, tradução livre). Em contraste, "Com o conceito de atividade subjetivante, nós abordamos as formas de percepção sensorial que não são levadas em consideração pelos conceitos científicos dominantes, ou o são apenas de forma marginal." (Id., p. 20, tradução livre). "A atividade subjetivante não visa a adquirir de imediato nem mesmo a se basear em conhecimentos objetiváveis sobre o ambiente, nem sobre as regras de ação correspondentes. Em primeiro plano, se põem sobretudo, no comércio com as pessoas e com as coisas, justamente suas particularidades e suas variações concretas, diferentes e - nesse sentido - únicas." (Ibid. p. 22, tradução livre).

5. A noção de "sensibilidade abstrata" é central na explicação da atividade subjetivante proposta por Böhle e Milkau. Preferimos traduzir "imagée" por percebida em imagens do que imaginado que remete mais ao sentido comum de abstração cognitiva do que a uma "sensibilidade abstrata" de acordo com os propósitos dos autores. Outra possibilidade seria traduzir por "figurada".

6. Algumas questões ainda permanecem em aberto para operar esta transformação entre descrição da atividade, seja na forma dos cursos da ação, e nos conteúdos desses modelos. A noção de "configuração de uso" (Duarte \& Lima, 2014; Lima \& Duarte, 2014) procura avançar um passo nessa direção.

7. Essa formalização baseada no curso da ação se situa, conforme sugerido pelos próprios autores, na mesma direção dos conceitos de análise de situações de referência, situações de ações características (SACs) e da análise da atividade futura (AAF), propostas por François Daniellou e Alain Garrigou (Garrigou et al., 1995). No entanto, enquanto no curso da ação se desenvolvem mais os conceitos e modelos de descrição da atividade, na abordagem da AAF se dá mais ênfase à construção social da intervenção em situação de projeto.

\section{RESUMOS}

Fracassos no desenvolvimento de tecnologias antropocêntricas, desde os anos 1950, sugerem que os princípios gerais de conceção abrem espaços para projetos sociotécnicos, mas são pouco operacionais para integrar o social, o subjetivo e o técnico. Este artigo mostra como a teoria do "curso da ação", que faz parte do campo da ergonomia da "atividade", contribui para efetivar essa integração. Com base num caso de automação de pequenas centrais hidroelétricas (PCHs), onde conceitos e métodos da teoria do curso de ação foram utilizados no projeto de novas situações de trabalho, demonstra-se, de forma mais ampla, a necessidade de uma praxeologia empírica para tratar interfaces H-H (formação) e H-M (automação), ou sistemas H-H-M. Teoricamente, as contribuições deste artigo situam-se no polo tecnológico do Programa de Pesquisa do Curso de Ação e, em termos práticos, constitui um alerta para que a indústria 4.0 não repita o mito da fábrica "sem homens".

Fracasos en el desarrollo de tecnologías antropocéntricas, desde la década de 1950, sugieren que principios generales del diseño abren espacios para proyectos socio-técnicos, pero no son muy operativos para integrar lo social, lo subjetivo y lo técnico. Este artículo muestra cómo la teoría del "curso de acción" (TCA), que forma parte del campo de la ergonomía de la "actividad", contribuye a efectuar esta integración. Utilizando un caso de automatización de pequeñas centrales hidroeléctricas, donde se emplearon conceptos y métodos de la TCA en el diseño de nuevas situaciones de trabajo, se demuestra la necesidad de una praxeología empírica para manejar interfaces H-H (capacitación), H-M (automatización), o sistemas H-H-M. Teóricamente, 
los aportes de este artículo se ubican en el polo tecnológico del Programa de Investigación del Curso de Acción y, en términos prácticos, es una alerta para que la Industria 4.0 no repita el mito de la fábrica "sin hombres".

Depuis la décennie de 1950, les échecs de développement de technologies anthropocentriques laissent à penser que les principes de conception de projets sociotechniques sont peu opérationnels pour articuler les aspects sociaux, subjectifs et techniques. Cet article démontre comment la théorie du "cours d"action", qui appartient au champ de l'ergonomie de "l'activité", contribue à rendre cette articulation plus effective. Sur la base d'un cas d'automation de petites centrales hydro-électriques ( $\mathrm{PCHs}$ ), où des concepts et méthodes de la théorie du cours d"action ont été utilisés, nous démontrons la nécessité d'une praxéologie empirique pour traiter les interfaces entre H-H (formation) et $\mathrm{H}-\mathrm{M}$ (automation) des systèmes $\mathrm{H}-\mathrm{H}-\mathrm{M}$. Du point de vue théorique, les contributions de cet article s'inscrivent au niveau du pôle technologique du Programme de Recherche du Cours d"Action et, en termes pratiques, il s'agit d'une alerte afin que l'industrie 4.0 ne reproduise pas le mythe de l'usine "sans hommes".

Since the 1950s, failures in the development of anthropocentric technologies suggest that general design principles open the way for socio-technical projects. However, the latter do not sufficiently integrate the social, the subjective and the technical aspects underlying any kind of industrial project. This paper shows how the "course of action" theory, which is part of the "activity" ergonomics field, supports this integration. This is achieved by showing how the concepts and methods of the course of action theory, used to design new work situations when automating small hydroelectric power plants (SHPPs), leads to a broader empirical praxeology for addressing H-H (training) and H-M (automation) interfaces, or H-H-M systems. Theoretically, this paper contributes to the technological pole of the Research Program of the Course of Action while, in practical terms, it warns Industry 4.0 professionals not to repeat the old myth (and expression) of the "manless factory".

\section{ÍNDICE}

Mots-clés: cours d'action, representamen, projet anthropocentré, savoir tacite, industrie 4.0 Palavras-chave: curso de ação, representamen, projeto antropocêntrico, conhecimento tácito, indústria 4.0

Palabras claves: curso de acción, representamen, proyecto antropocéntrico, conocimiento tácito, industria 4.0

Keywords: course of action, representation, anthropocentric project, tacit knowledge, 4.0 industry

\section{AUTORES}

\section{FRANCISCO DE PAULA ANTUNES LIMA}

Universidade Federal de Minas Gerais - UFMG ; Av. Pres. Antônio Carlos, 6627, Pampulha, CEP31270-901, Belo Horizonte, MG, Brasil, fpalima@ufmg.br

\section{RODRIGO RIBEIRO}

Universidade Federal de Minas Gerais - UFMG ; Av. Pres. Antônio Carlos, 6627, Pampulha, CEP31270-901, Belo Horizonte, MG, Brasil, rodrigoribeiro@ufmg.br 


\section{MARCELLE LA GUARDIA}

Situated Consultoria e Pesquisa - Avenida Prudente de Morais, 621, Santo Antônio, CEP 30350-143, Belo Horizonte, MG, Brasil

marcelle.laguardia.lara@gmail.com

\section{SAMIRA NAGEM}

Situated Consultoria e Pesquisa - Avenida Prudente de Morais, 621, Santo Antônio, CEP 30350-143, Belo Horizonte, MG, Brasil

sanagemlima@gmail.com 